\title{
Radiative energy balance of Venus: An approach to parameterize thermal cooling and solar heating rates
}

\author{
R. Haus ${ }^{a^{*}}$, D. Kappel ${ }^{\text {b }}$ G. Arnold \\ ${ }^{\text {a}}$ University of Münster (WWU), Institute for Planetology, Wilhelm-Klemm-Str.10, 48149 \\ Münster, Germany, rainer.haus@gmx.de \\ ${ }^{\mathrm{b}}$ German Aerospace Center (DLR), Institute of Planetary Research, Rutherfordstrasse 2, 12489 \\ Berlin, Germany, dkappel@gmx.net, gabriele.arnold@dlr.de
}

\begin{abstract}
Thermal cooling rates $\mathrm{Q}^{\mathrm{C}}$ and solar heating rates $\mathrm{Q}^{\mathrm{H}}$ in the atmosphere of Venus at altitudes between 0 and $100 \mathrm{~km}$ are investigated using the radiative transfer and radiative balance simulation techniques described by Haus et al. (2015b, 2016). $\mathrm{Q}^{\mathrm{C}}$ strongly responds to temperature profile and cloud parameter changes, while $\mathrm{Q}^{\mathrm{H}}$ is less sensitive to these parameters. The latter mainly depends on solar insolation conditions and the unknown UV absorber distribution.

A parameterization approach is developed that permits a fast and reliable calculation of temperature change rates Q for different atmospheric model parameters and that can be applied in General Circulation Models to investigate atmospheric dynamics. A separation of temperature, cloud parameter, and unknown UV absorber influences is performed. The temperature response parameterization relies on a specific altitude and latitude-dependent cloud model. It is based on an algorithm that characterizes Q responses to a broad range of temperature perturbations at each level of the atmosphere using the Venus International Reference Atmosphere (VIRA) as basis temperature model. The cloud response parameterization considers different temperature conditions and a range of individual cloud mode factors that additionally change cloud optical depths as determined by the initial latitude-dependent model. $\mathrm{A} \mathrm{Q}^{\mathrm{H}}$ response parameterization for abundance changes of the unknown UV absorber is also included. Deviations between accurate calculation and parameterization results are in the order of a few tenths of $\mathrm{K} /$ day at altitudes below $90 \mathrm{~km}$.
\end{abstract}

The parameterization approach is used to investigate atmospheric radiative equilibrium (RE) conditions. Polar mesospheric RE temperatures above the cloud top are up to $70 \mathrm{~K}$ lower and equatorial temperatures up to $10 \mathrm{~K}$ higher than observed values. This radiative forcing field is balanced by dynamical processes that maintain the observed thermal structure.

\section{Introduction}

The conversion of radiative energy in a planetary atmosphere stimulates dynamical processes at all altitudes and forces climate and weather phenomena via a number of coupling effects. The general processes being responsible to maintain the zonal superrotation in the troposphere and mesosphere of Venus (where the winds blow

up to four times faster than the solid body rotates) and its transition to the sub-solar to anti-solar circulation in the thermosphere are still poorly understood (Schubert et al., 2007). Different General Circulation Models (GCMs) for Venus' atmosphere have been developed during the past years and are currently under further development. They intend to simulate atmospheric circulation processes and observed dynamical properties 
(e.g. Lee and Richardson, 2010; Lebonnois et al., 2010; Rodin et al., 2013). GCMs have to rely on parameterized descriptions of radiative heating and cooling processes due to limited overall numerical resources.

Calculations of accurate quasimonochromatic downward and upward directed radiation fluxes inside the atmosphere that consider both gaseous and particulate atmospheric absorption, emission, and multiple scattering processes are only possible on the basis of very time consuming numerical procedures. The overall broad spectral range from 0.1 to $1000 \mu \mathrm{m}$ has to be addressed where the individual contributions of atmospheric constituents at ultraviolet (0.1-0.4 $\mu \mathrm{m})$, visible $(0.4-0.7 \mu \mathrm{m})$, and infrared $(0.7-1000 \mu \mathrm{m})$ wavelengths are very different. Calculations can be separately performed for thermal $(1.67-1000 \mu \mathrm{m}, 10$ $\left.6000 \mathrm{~cm}^{-1}\right)$ and solar $(0.125-1000 \mu \mathrm{m}, 10-$ $80000 \mathrm{~cm}^{-1}$ ) flux components. Wavelengthintegrated quantities and diurnal averages of resulting net fluxes and their altitude divergences are then used to determine temperature change rates in terms of thermal cooling rates and solar heating rates at each altitude, latitude and for different local times. The results strongly depend on the used atmospheric models both with respect to thermal structure and cloud composition. It is impossible to incorporate accurate radiative balance calculations that take several hours on current computer hardware into GCMs, and the use of time efficient parameterization approaches is urgently required.

The main methodical aspects to investigate the radiative energy balance in the middle and lower atmosphere of Venus $(0-100 \mathrm{~km})$ were described by Haus et al. (2015b). Variations of initial atmospheric model data sets (also denoted as 'standard' in the following) were used to calculate responses of radiative fluxes and temperature change rates to atmospheric and spectroscopic parameter variations. A second paper (Haus et al., 2016) has then investigated atmospheric radiation fluxes (F) and temperature change rates $(\mathrm{Q})$ that are based on improved three-dimensional atmospheric models (altitude-latitude-local time) mainly retrieved from VIRTIS-M-IR data. An additional focus of that paper was the response of Q to the replacement of VIRTIS temperature profiles by those obtained from VeRa data. VIRTIS (Visible and Infrared Thermal Imaging Spectrometer; Piccioni et al., 2007; Drossart et al., 2007; Arnold et al., 2012) and VeRa (Venus Express Radio science experiment; Häusler et al., 2006) were two of the experiments aboard ESA's Venus Express (VEX) mission. Retrieval results from VIRTIS-M-IR measurements during eight Venus solar days between April 2006 and October 2008 were extensively described by Haus et al. (2013, 2014, 2015a). They comprised new information on mesospheric nightside thermal structure and cloud features and on trace gas distributions in the lower atmosphere. Resulting maps for the southern hemisphere covered parameter variations with altitude, latitude, local time, and mission time. The most important retrieval results have been summarized in the recently published paper by Haus et al. (2016).

Only few information on radiative transfer parameterization approaches can be found in the literature. The only recent papers that describe a success in this direction are those of Mendonca et al. (2015) and Lebonnois et al. (2015). Lebonnois et al. applied the NER (Net Exchange Rate) formalism developed by Eymet et al. (2009). This method only allows a user to consider infrared radiative transfer, that is, a parameterization of thermal cooling rates. Moreover, the radiative budget analysis of Lebonnois et al. is a one-dimensional global average approach. The impact of latitudinal variations of atmospheric parameters was not considered so far. Globally averaged solar heating rates were taken from other literature sources (e.g. Crisp, 1986). Mendonca et al. also applied a layer exchange radiative transfer code for thermal radiation that is based on an absorptivity/emissivity formulation (neglecting scattering) and the diffusivity approximation for emission angle integration. Solar radiation fluxes were 
calculated using a two-stream solution whereby incorporating the $\delta$-Eddington approximation and a layer-adding method. Several averaging steps (e.g. over gaseous absorption features originally determined by a k-distribution method) permit a fast recalculation of atmospheric radiation fluxes. A latitudinal uniform cloud distribution was assumed based on the equatorial model developed by Crisp (1986).

It is the main goal of the present paper to utilize the comprehensive results of radiative energy balance analyses recently performed by Haus et al. (2016) and to investigate possible approaches to parameterize the calculation of both thermal cooling rates $Q^{C}$ and solar heating rates $\mathrm{Q}^{\mathrm{H}}$. Section 2 gives an overview of $Q$ results obtained by Haus et al. (2016) for different sets of temperature profiles, cloud parameters, and abundances of the unknown UV absorber (UVA). Section 3 describes the newly developed parameterization technique used to calculate $\mathrm{Q}^{\mathrm{C}}$ and $\mathrm{Q}^{\mathrm{H}}$ for changing atmospheric thermal conditions. Section 4 presents parameterized $\mathrm{Q}$ results for cloud parameter and UVA variations. Section 5 provides a discussion that is related to an atmosphere being in full radiative equilibrium. The main results are summarized in Section 6.

\section{Accurate calculation results of temperature change rates for different atmospheric models}

The terminology 'accurate' is used here and in the following to characterize methods and results that are based on quasimonochromatic calculations of radiation fluxes and temperature change rates. In contrast, the approximative method described in Sections 3 and 4 is denoted as 'parameterization'.

\subsection{Thermal structure}

Fig. 1 shows a comparison of zonally averaged mean VIRTIS, VeRa, VIRA-2, and VIRA-1 atmospheric model temperature profiles at 20 and $65^{\circ}$ (displays A-B) as well as resulting altitude profiles of zonally averaged mean thermal cooling rates $\left(Q^{C}\right.$, displays $\mathrm{C}$ and $\mathrm{D}$ ) and solar heating rates $\left(\mathrm{Q}^{\mathrm{H}}\right.$, displays $\mathrm{E}$ and $\left.\mathrm{F}\right)$. VIRTIS temperatures (that is, atmospheric temperatures retrieved from VIRTIS data) are primarily valid for the southern hemisphere, while VIRA (Venus International Reference Atmosphere) and VeRa temperatures result from observations over both hemispheres. High similarities between northern and southern hemisphere temperature fields as retrieved by Haus et al. (2013) indicate global N-S axial symmetry of atmospheric temperature structure, however. The notation 'mean' accentuates the fact that depicted profiles correspond to the mean state of the atmosphere obtained from VIRTIS and VeRa retrievals and VIRA-2 averages over local time.

VIRA-1 (Seiff et al., 1985) is the model that will be used as initial or 'basis' model of Venus' atmospheric thermal structure in the following assuming identical thermal regimes on the nightside (N) and dayside (D) of the planet up to $95 \mathrm{~km}$. Corresponding pressure profiles for each temperature model are always determined by integrating the hydrostatic equation and using the ideal gas law and a mean surface pressure of 92.1 bar at zero elevation, taking into account the altitude dependence of the gravity acceleration. VIRA-1 considers data from early US and USSR Venus missions and (for that time) latest results from the Pioneer Venus mission 1978. VIRA-2 (Zasova et al., 2006) summarizes temperature results obtained from missions that had been completed after the earlier work on VIRA-1. It includes results from infrared thermal soundings performed by Venera-15 (1983), the Vega 2 entry probes (1985), and Galileo NIMS (1990) as well as radio occultation profiles from Venera-15/16 and Magellan (1990) data. The notation VIRA-2 was originally introduced by Moroz and Zasova (1997) and is also used here. VIRA-2 provides latitude and solar longitudedependent temperature profiles at altitudes between 50 and $100 \mathrm{~km}$. To construct a pure latitude-dependent model, these data have 
Haus, R., et al., ICARUS 284, 216-232 (2017) Doi: 10.1016/j.icarus.2016.11.025 Preprint been averaged over solar longitude (local corresponds to VIRA-1 where all profiles are time) here. Below $40 \mathrm{~km}$, VIRA-2
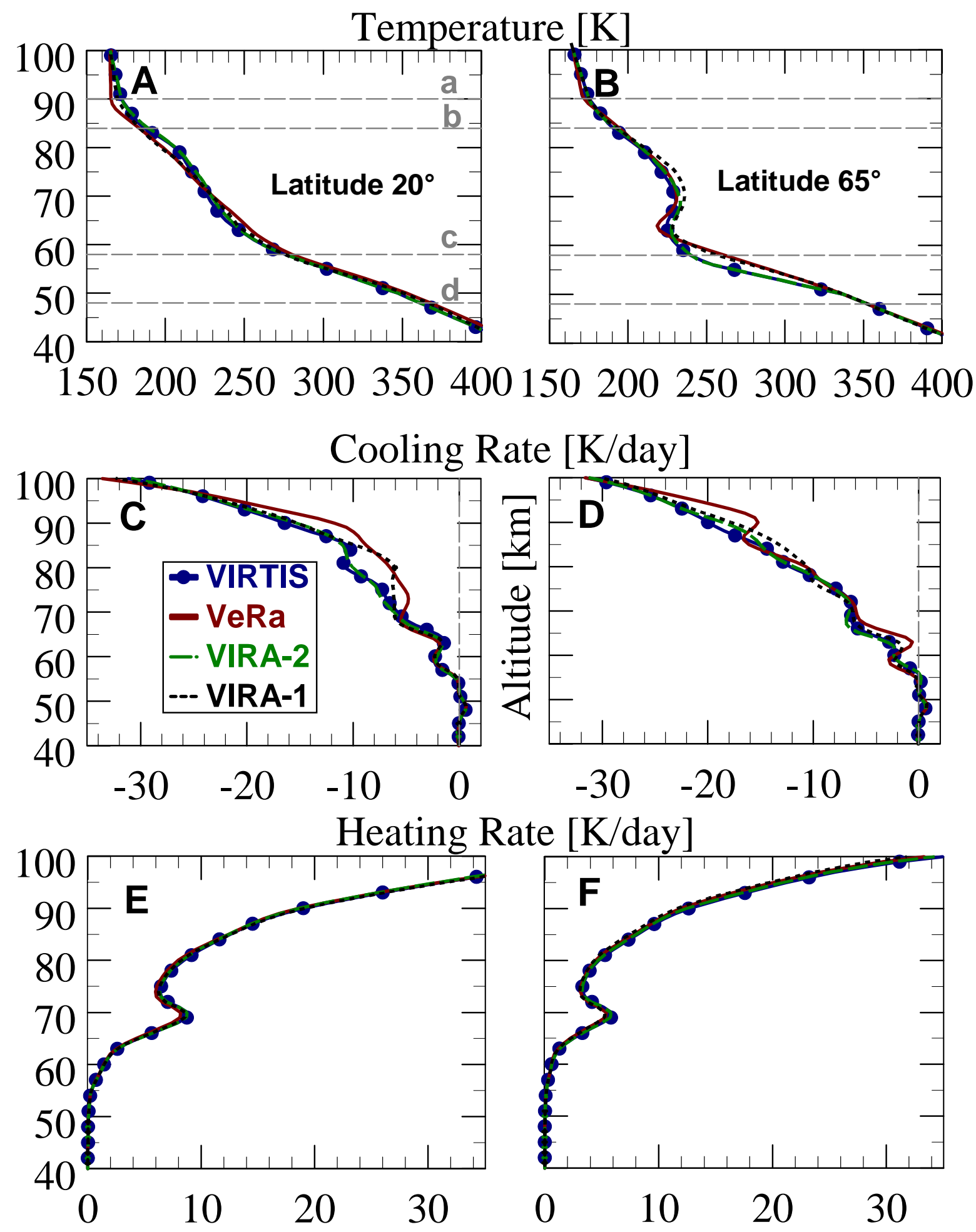

Fig. 1. Comparison of zonally averaged mean VIRTIS, VeRa, VIRA-2, and VIRA-1 atmospheric model temperature profiles at latitudes of 20 and $65^{\circ}(\mathrm{A}-\mathrm{B})$ and resulting thermal cooling rates $\mathrm{Q}^{\mathrm{C}}(\mathrm{C}-\mathrm{D})$ and solar heating rates $\mathrm{Q}^{\mathrm{H}}(\mathrm{E}-\mathrm{F})$. For explanations of horizontal broken lines a-d in displays $\mathrm{A}$ and $\mathrm{B}$ see text.

local time-independent models from the outset. VIRA-2 profiles between 40 and 50 $\mathrm{km}$ are obtained by linear interpolation between both models. VIRA-1 and -2 profiles above $90 \mathrm{~km}$ (horizontal broken lines in displays A and B of Fig. 1 marked by ' $a$ ') result from a linear interpolation between the latitude-dependent temperatures 
at $90 \mathrm{~km}$ and a fixed value of $165 \mathrm{~K}$ at 100 $\mathrm{km}$. A latitude-independent linear nightside profile then extends to $140 \mathrm{~K}$ at $140 \mathrm{~km}$ altitude.

The temperatures on the day- and nightside of Venus start to diverge at altitudes above $95 \mathrm{~km}$. At this altitude, VIRA-1 and VIRA-2 profiles below $95 \mathrm{~km}$ converge to about 170 $\mathrm{K}$. For present flux calculations, the top of the atmosphere (TOA) is set to an altitude of $140 \mathrm{~km}$ to avoid discontinuities at $100 \mathrm{~km}$ (the assumed upper boundary of Venus' mesosphere). A latitude-independent dayside temperature profile is used between 100 and $140 \mathrm{~km}$ (Keating et al., 1985). Linear interpolations connect the VIRA nightside model (VIRA-N) at $95 \mathrm{~km}$ with this data set to construct the day time profile (VIRA-D).

Temperature field retrievals from VIRTIS radiance measurements in the $4.3 \mu \mathrm{m} \mathrm{CO}$ absorption band were only performed using nightside data, since it is very difficult to discriminate between thermal radiation, scattered sunlight and $\mathrm{CO}_{2}$ non-LTE emission features at these wavelengths from VIRTIS dayside measurements. Due to instrumental noise in the main center of the $4.3 \mu \mathrm{m}$ band, the effective upper sounding altitude of VIRTIS-M-IR is $84 \mathrm{~km}$. Retrieved temperature profiles above $84 \mathrm{~km}$ (horizontal broken lines in displays A and B marked by ' $b$ ') were modified by linear interpolations between 84 and $90 \mathrm{~km}$ where the $90 \mathrm{~km}$ temperatures correspond to VIRA2 values. VIRA-2 was used as initial temperature model in the retrieval procedure. Below about $58 \mathrm{~km}$ (horizontal broken lines marked by 'c'), retrieved VIRTIS temperatures tend to follow the latitudedependent initial temperature profiles due to lacking weighting function information.

VeRa measurements provided temperature profiles at altitudes between 45 and $90 \mathrm{~km}$. Nightside data are used here. The upper altitude bound is determined by assumptions on the boundary temperature at $100 \mathrm{~km}$ that may strongly affect the retrieval results down to $80-90 \mathrm{~km}$. The actual lower bound is due to the observation geometry that limited sounding to altitudes between about $47 \mathrm{~km}$ at equatorial and $42 \mathrm{~km}$ at polar latitudes (Tellmann et al., 2009, 2012). Retrieval results obtained at regions close to measurement sensitivity bounds are especially prone to possible errors and should always be used with care. This holds true for both VeRa and VIRTIS data. Thus, it must be mentioned that calculated temperature change rates based on temperature retrieval results from VIRTIS and VeRa data at altitudes above $90 \mathrm{~km}$ (where lacking retrieval data were substituted in the way described above) and comparisons of results are less reliable than for lower altitudes above $58 \mathrm{~km}$. The horizontal broken lines marked by ' $d$ ' indicate that linear interpolations connect VeRa temperatures at $48 \mathrm{~km}$ with the latitude-independent VIRA-2 value at $32 \mathrm{~km}$, which is equivalent to VIRA-1 and VIRTIS.

Displays $\mathrm{A}$ and $\mathrm{B}$ in Fig. 1 illustrate that VIRTIS, VeRa, VIRA-1, and VIRA-2 temperatures at low latitudes usually agree within $10 \mathrm{~K}$. The same holds true at mid latitudes up to about $45^{\circ}$. At altitudes above $75 \mathrm{~km}$, VeRa temperatures at low and mid latitudes are mostly lower than VIRTIS values. The differences reach $-8 \mathrm{~K}$ at $88 \mathrm{~km}$ near the equator. Partly larger temperature differences occur at altitudes between 52 and $60 \mathrm{~km}$ where VIRTIS and VIRA-2 temperatures near $55 \mathrm{~km}$ and $60^{\circ}$ are 20-25 $\mathrm{K}$ lower than VeRa and VIRA-1 results. Recall that VIRTIS temperatures below 58$60 \mathrm{~km}$ (broken lines c) approach VIRA-2 data. Compared with VIRA-1, other profiles mainly at high latitudes also differ by up to $10 \mathrm{~K}$ between 65 and $75 \mathrm{~km}$. The comparatively small temperature differences near $100 \mathrm{~km}$ and below $45 \mathrm{~km}$ are due to the use of the above described linear temperature profile interpolations, although low latitude VeRa profiles near $40 \mathrm{~km}$ still deviate from the other ones by up to $4 \mathrm{~K}$.

The zonally averaged mean thermal cooling rates in Fig. 1 (displays $\mathrm{C}$ and $\mathrm{D}$ ) are based on the temperature profiles shown in displays A and B. Temperature change rates are calculated according to the equations 
Haus, R., et al., ICARUS 284, 216-232 (2017)

given by Haus et al. (2016). Cooling rates may heavily respond to variations of atmospheric thermal structure. Pure temperature effects are strongest pronounced at altitudes between 60 and $95 \mathrm{~km}$ where absolute $\mathrm{Q}^{\mathrm{C}}$ values usually increase with increasing temperature. Smaller VeRa temperatures between 70 and $90 \mathrm{~km}$ at low latitudes, for example, result in smaller absolute $\mathrm{Q}^{\mathrm{C}}$ values. Note that cooling rates carry a minus sign only per convention. The VeRa temperature around $65 \mathrm{~km}$ at higher latitudes is lower than that of other temperature models, and the VeRa cooling rate has consequently also a local (absolute) minimum there.

Heating rates (displays $\mathrm{E}$ and $\mathrm{F}$ ) also strongly depend on latitude. But they generally respond much weaker to atmospheric temperature changes than cooling rates do and are almost insensitive to small temperature changes as shown by Haus et al. (2016). On the other hand, in the thick atmosphere of Venus, decreasing insolation with increasing distance from equator results in much smaller heating rates at high latitudes that cannot be compensated by the comparatively stronger absorption due to longer atmospheric path lengths.

It is important to stress that the depicted Q results in Fig. 1 for the four temperature profiles are based on cloud mode abundances, cloud top altitudes, and trace gas abundances that were retrieved from VIRTIS-M-IR measurements. The recently proposed model of the unknown UV absorber (Haus et al., 2016) is utilized as standard model. The overall response of the radiative energy balance to trace gas variations is rather small in the mesosphere (Haus et al., 2015b), but variations (especially $\mathrm{H}_{2} \mathrm{O}$ and $\mathrm{SO}_{2}$ ) near the cloud base may become more important. Hence, available data on latitudinal variability of
Doi: 10.1016/j.icarus.2016.11.025 Preprint

trace gas abundances are included in the present study. In contrast with trace gas variations, the observed cloud parameter variability may significantly alter temperature change rates as the unknown UV absorber (UVA) does in case of solar heating. Cloud and UVA influences are described in more detail in Section 2.2.

Fig. 2 illustrates thermal cooling rate differences as functions of latitude and altitude when two different temperature data sets are used in each case, $\Delta Q^{\mathrm{C}}($ set 1 , set 2$)=$ $Q^{C}($ set 1$)-Q^{C}($ set 2$)$. Set 2 in displays A-C corresponds to VIRA-1, while set 1 is VIRTIS (A), VeRa (B), and VIRA-2 (C), respectively. Display $\mathrm{D}$ shows the differences $\Delta \mathrm{Q}^{\mathrm{C}}$ (VeRa, VIRTIS). Positive differences characterize weaker set 1 cooling. Cooling rates for the four temperature models usually agree within \pm 3 $\mathrm{K} /$ day at altitudes below $80 \mathrm{~km}$. Larger differences up to 5-6 K/day occur near 90 $\mathrm{km}$, especially when VeRa and VIRA-1 (B) or VeRa and VIRTIS (D) results are compared. By analogy with Fig. 2, Fig. 3 shows solar heating rate differences. Positive values characterize stronger set 1 heating. Below about $90 \mathrm{~km}$, they do rarely exceed $\pm 1 \mathrm{~K} /$ day. Maximum deviations up to \pm 2.5 $\mathrm{K} /$ day are found at mid latitudes near 100 $\mathrm{km}$.

\subsection{Clouds and the unknown UV absorber}

The used standard model of cloud mode altitude profiles (Haus et al., 2016) facilitates analytical descriptions of four-modal particle altitude distributions (modes 1, 2, 2', 3) where all modes are assumed to consist of spherical $\mathrm{H}_{2} \mathrm{SO}_{4}$ aerosols at $75 \mathrm{wt} \%$ solution. The particle number density altitude profile $\mathrm{N}(\mathrm{z})$ is calculated according to Eq. (1),

$$
\mathrm{N}(\mathrm{z})=\left\{\begin{array}{ll}
\mathrm{N}_{0}\left(\mathrm{z}_{\mathrm{b}}\right) \exp \left[-\left(\mathrm{z}-\left(\mathrm{z}_{\mathrm{b}}+\mathrm{z}_{\mathrm{c}}\right)\right) / \mathrm{H}_{\mathrm{up}}\right], & \mathrm{z}>\left(\mathrm{z}_{\mathrm{b}}+\mathrm{z}_{\mathrm{c}}\right) \\
\mathrm{N}_{0}\left(\mathrm{z}_{\mathrm{b}}\right), & \left(\mathrm{z}_{\mathrm{b}}+\mathrm{z}_{\mathrm{c}}\right) \geq \mathrm{z} \geq \mathrm{z}_{\mathrm{b}} \\
\mathrm{N}_{0}\left(\mathrm{z}_{\mathrm{b}}\right) \exp \left[-\left(\mathrm{z}_{\mathrm{b}}-\mathrm{z}\right) / \mathrm{H}_{\mathrm{lo}}\right], & \mathrm{z}<\mathrm{z}_{\mathrm{b}}
\end{array}\right\} .
$$

The description of individual quantities and their mode-dependent numbers are given in Table 1 . 


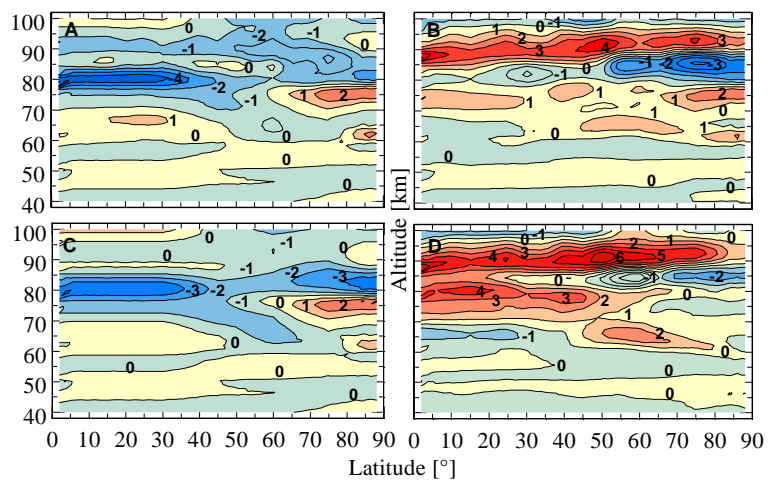

Fig. 2. Differences $\Delta Q^{C}$ [K/day] of zonally averaged mean thermal cooling rates as functions of latitude and altitude for different temperature data sets. (A) VIRTIS vs. VIRA-1, (B) VeRa vs. VIRA-1, (C) VIRA-2 vs. VIRA-1, (D) VeRa vs. VIRTIS.

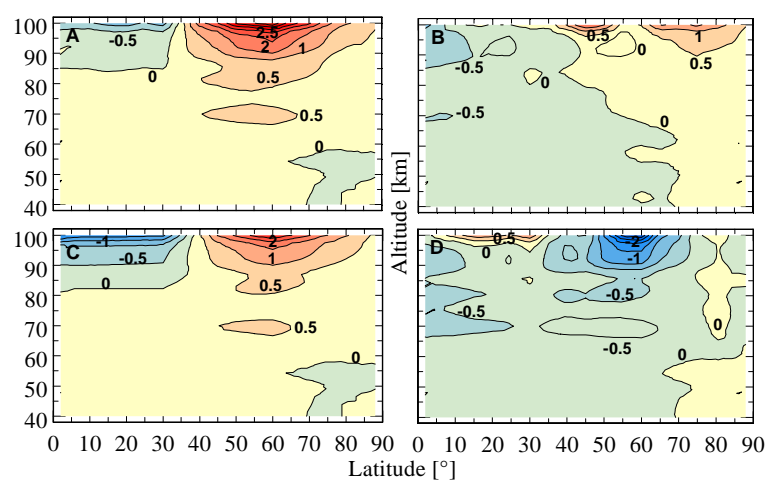

Fig. 3. Same as Fig. 2 but for differences $\Delta Q^{\mathrm{H}}$ [K/day].

Mode 2 parameters of the standard cloud model as well as the particle number densities $\mathrm{N}_{0}$ for modes 1,2 , and 3 are additionally modified in dependence on latitude. This was required to fit measured VIRTIS-M-IR spectra in the $4.3 \mu \mathrm{m} \mathrm{CO}_{2}$ absorption band and in the $2.3 \mu \mathrm{m}$ transparency window ranges, respectively (Haus et al., 2016). The lower altitude of constant peak particle number density $\mathrm{z}_{\mathrm{b}}(2)$ (in earlier papers also called 'lower base of mode 2 peak altitude') is shifted from $65 \mathrm{~km}$ downward step by step with increasing latitude, while the upper scale height $\mathrm{H}_{\text {up }}(2)$ is reduced. These data are summarized in Table 2.

Cloud opacity is the most vigorously varying state parameter of Venus' atmosphere. Not only with respect to latitude but also regarding local time and time, the cloud formation patterns are very complex. Variations of cloud opacity were retrieved from VIRTIS-M-IR data introducing socalled cloud mode factors $\mathrm{MF}_{1,2}$ for modes 1 and 2, and cloud mode factor $\mathrm{MF}_{3}$ for mode 3. The cloud mode factors $M F_{i}$ change $N_{0}$ and thereby column densities independently for each cloud mode $i$, but maintain its altitude distribution that is determined by the standard cloud model (Table 1) and the parameters given in Table 2. Mode 1 aerosols play a minor role at IR wavelengths. They were treated together with mode 2 aerosols in the $\mathrm{MF}_{\mathrm{i}}$ retrieval procedures. Mode 2' abundance changes could not be retrieved, and $\mathrm{MF}_{2},=1.0$ was always used assuming that possible changes were reflected by mode 3 variations. The retrieved zonally averaged mean parameters $\mathrm{MF}_{1,2}$ and $\mathrm{MF}_{3}$ are given in Table 3.

Table 1. Parameters of the standard cloud model: Single-mode characteristics.

\begin{tabular}{|c|c|c|c|c|}
\hline Mode & 1 & 2 & 2 & 3 \\
\hline $\begin{array}{l}\text { Lower altitude of constant peak particle } \\
\text { number density, } \mathrm{z}_{\mathrm{b}}[\mathrm{km}]\end{array}$ & 49.0 & $65.0^{\mathrm{a}}$ & 49.0 & 49.0 \\
\hline $\begin{array}{l}\text { Layer thickness of constant peak particle } \\
\text { number density, } \mathrm{z}_{\mathrm{c}}[\mathrm{km}]\end{array}$ & 16.0 & 1.0 & 11.0 & 8.0 \\
\hline Upper scale height $\mathrm{H}_{\text {up }}[\mathrm{km}]$ & $3.5^{\mathrm{b}}$ & $3.5^{\mathrm{a}, \mathrm{b}}$ & 1.0 & 1.0 \\
\hline Lower scale height $\mathrm{H}_{\mathrm{lo}}[\mathrm{km}]$ & $1.0^{\mathrm{c}}$ & 3.0 & 0.1 & 0.5 \\
\hline Particle number density $\mathrm{N}_{0}$ at $\mathrm{z}_{\mathrm{b}}\left[\mathrm{cm}^{-3}\right]$ & $193.5^{\mathrm{a}}$ & $100^{\mathrm{a}}$ & 50 & $14^{\mathrm{a}}$ \\
\hline \multicolumn{5}{|c|}{$\begin{array}{l}{ }^{a} \text { Values change with latitude. }{ }^{\mathrm{b}} \text { An upper scale height of } 2 \mathrm{~km} \text { is assumed above } 80 \mathrm{~km} \text {. } \\
{ }^{\mathrm{c}} \text { A lower haze is considered below } 45 \mathrm{~km} \text { using } \mathrm{H}_{\mathrm{lo}}=5 \mathrm{~km} \text {. } \\
\text { The total cloud ensemble yields an opacity of } 35.0 \text { and a cloud top altitude } \mathrm{z}_{\mathrm{t}}=70.81 \mathrm{~km} \text { at } 1\end{array}$} \\
\hline
\end{tabular}


Table 2. Latitude dependence of mode 2 cloud parameters. $\varphi$ : Latitude $\left[{ }^{\circ}\right], \mathrm{z}_{\mathrm{b}}$ : Lower altitude of constant peak particle number density $[\mathrm{km}], \mathrm{H}_{\text {up }}$ : Upper scale height [km].

\begin{tabular}{lcccccccc}
\hline$\varphi$ & $0-45$ & 50 & 55 & 60 & 65 & 70 & 75 & $80-90$ \\
\hline $\mathrm{Z}_{\mathrm{b}}$ & 65.0 & 65.0 & 65.0 & 64.5 & 63.8 & 63.1 & 62.5 & 62.0 \\
$\mathrm{H}_{\text {up }}$ & 3.5 & 3.4 & 3.2 & 2.6 & 2.0 & 1.0 & 0.6 & 0.5 \\
\hline
\end{tabular}

Table 3. Latitude dependence of retrieved cloud mode abundance factors. $\varphi$ : Latitude $\left[{ }^{\circ}\right], \mathrm{MF}_{1,2}$ : Mode 1 and 2 factors, $\mathrm{MF}_{3}$ : Mode 3 factor.

\begin{tabular}{lcccccccccccccc}
\hline$\varphi$ & $0-15$ & 20 & 25 & 30 & 35 & 40 & 45 & 50 & 55 & 60 & 65 & 70 & 75 & $80-90$ \\
\hline $\mathrm{MF}_{1,2}$ & 0.98 & 0.99 & 1.00 & 0.98 & 0.94 & 0.86 & 0.81 & 0.73 & 0.67 & 0.64 & 0.61 & 0.59 & 0.47 & 0.36 \\
$\mathrm{MF}_{3}$ & 1.30 & 1.26 & 1.23 & 1.17 & 1.13 & 1.06 & 1.03 & 1.04 & 1.09 & 1.22 & 1.51 & 1.82 & 2.02 & 2.09 \\
\hline
\end{tabular}

The clouds of Venus strongly influence radiative temperature change rates of the atmosphere. Consideration of latitudedependent cloud parameters according to Tables 2 and 3 does seriously change both thermal cooling and solar heating rates especially at mid and high latitudes compared with a neglect of this opacity variation. This is visualized in Fig. 4 in terms of latitude and altitude-dependent differences $\Delta \mathrm{Q}($ set 1 , set 2$)=\mathrm{Q}($ set 1$)-\mathrm{Q}($ set 2$)$ where set 1 and set 2 denote actually retrieved and latitude-independent model cloud parameter conditions, respectively. Positive values characterize weaker set 1 cooling (display A) and stronger set 1 heating (display B). The calculations are based on VIRA-1 temperature profiles. Consideration of retrieved cloud parameters significantly reduces thermal cooling poleward of about $50^{\circ}$ and at altitudes between 65 and $80 \mathrm{~km}$,

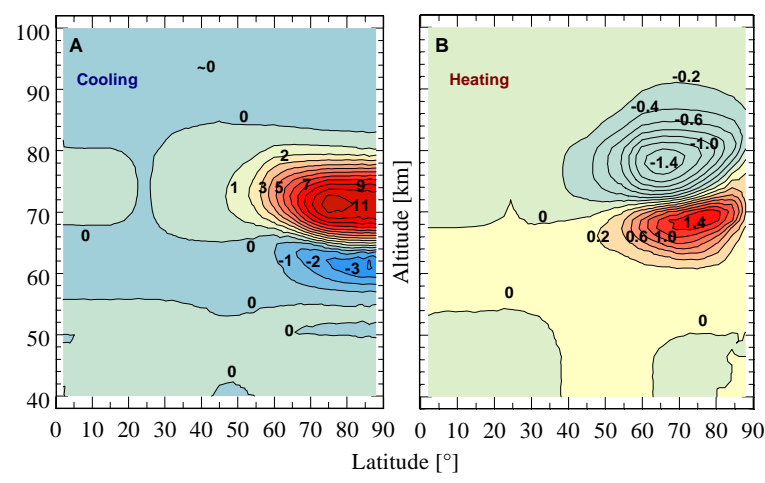

Fig. 4. Differences $\Delta \mathrm{Q}[\mathrm{K} /$ day $]$ of zonally averaged mean thermal cooling rates (A) and solar heating rates (B) as functions of latitude and altitude when mean latitudinal variations of cloud parameters are considered or not.

while stronger cooling is observed at polar latitudes between 55 and $65 \mathrm{~km}$. The use of retrieved cloud parameters also reduces solar heating poleward of about $40^{\circ}$ at altitudes between 72 and $90 \mathrm{~km}$, and stronger heating occurs in that latitude range between 60 and $72 \mathrm{~km}$. This behavior of both cooling and heating rates is mainly due to decreasing cloud mode 2 abundances at higher latitudes. Cooling rate changes between 55 and $65 \mathrm{~km}$ are additionally forced by increasing cloud mode 3 abundances at polar latitudes. Heating rate responses are generally much smaller than cooling rate responses. Note the different isoline scales in displays A and B.

There is a broad depression in the observed spectral Bond albedo of Venus at wavelengths between 0.32 and about $0.8 \mu \mathrm{m}$ that cannot be explained by known absorption features of gases or clouds. Shortward of $0.32 \mu \mathrm{m}, \mathrm{SO}_{2} \mathrm{UV}$ absorption provides sufficient opacity to match the observed albedo features. A new model for this additional opacity source (the unknown UV absorber), which may be either composed of aerosol particles, gaseous molecules, solid atom conglomerates, or even mixtures of all these agents, was proposed by Haus et al. (2015b). The nominal altitude profile $\mathrm{N}(\mathrm{z})$ of particle number density peaks at a constant value of $10 \mathrm{~cm}^{-3}$ between 58 and $70 \mathrm{~km}$. The profile decreases with a scale height of $1 \mathrm{~km}$ above and below these bounds according to Eq. (1). Using these profiles, altitude-independent absorption cross-section spectra were calculated ('retrieved') that yield good fits of the Bond albedo spectrum presented by Moroz (1981). This way, the unknown absorber is not directly linked to cloud particle modes 1 or 2 (in contrast with 
assumptions in previous studies, e.g. Crisp, 1986; Pollack et al., 1980). This approach that is based on a suitable parameterization of optical properties permits an investigation of the absorber's radiative effects regardless of its chemical composition and independently of the used cloud model.

Fig. 5 illustrates latitude and altitudedependent heating rate differences $\Delta \mathrm{Q}^{\mathrm{H}}$ (set 1 , set 2) when the abundance of the unknown UV absorber is doubled (set 1). Set 2 refers to the nominal abundance factor of unity. When the unknown UV absorber is neglected in the simulation, the resulting 2D plot looks very similar to Fig. 5 but with negative numbers. Neglect of UVA would reduce solar heating around $70 \mathrm{~km}$ by about $4 \mathrm{~K} /$ day at the equator (equal to about a halving of overall heating), while doubling of UVA abundance provides up to $3.5 \mathrm{~K} /$ day more heating. The decrease of UVA influence with increasing latitude (mainly from mid to polar latitudes) is due to the general decrease of solar heating rates with decreasing insolation. Thermal cooling rates are not affected by UVA variations, since significant cooling contributions only occur longward of $1.67 \mu \mathrm{m}$.

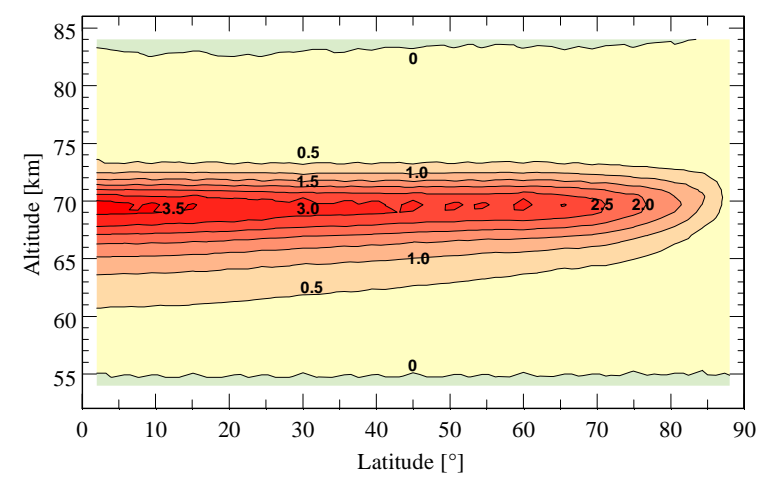

Fig. 5. Differences $\Delta Q^{\mathrm{H}}$ [K/day] of zonally averaged mean solar heating rates as functions of latitude and altitude due to doubling of UVA abundance.

\section{Parameterization of temperature change rates as functions of thermal structure}

\subsection{Description of method}

Figs. 1-5 have shown that thermal cooling rates $\mathrm{Q}^{\mathrm{C}}$ strongly respond to changes of atmospheric thermal structure and cloud distribution. Heating rates $\mathrm{Q}^{\mathrm{H}}$ are less sensitive to temperature variations but may also significantly depend on cloud distribution and parameters of the unknown UV absorber. The study of atmospheric dynamics using General Circulation Models (GCMs) requires fast recalculations of temperature change rates in response to a changing atmospheric environment. Accurate radiative balance calculations take several hours (especially in case of solar heating), and it is impossible to incorporate them into GCMs. Thus, a technique that permits a parameterization of atmospheric temperature change rates has to be used.

The basic idea to perform a parameterization of $\mathrm{Q}^{\mathrm{C}}$ and $\mathrm{Q}^{\mathrm{H}}$ as functions of the atmospheric temperature profile is a calculation of $Q$ responses to certain defined temperature perturbations $\mathrm{T}^{\mathrm{D}}$ at each level of the atmosphere using an initial (or basis) temperature model. Corresponding results can then be used to determine actual Q values based on temperature differences between actual and basis temperature fields.

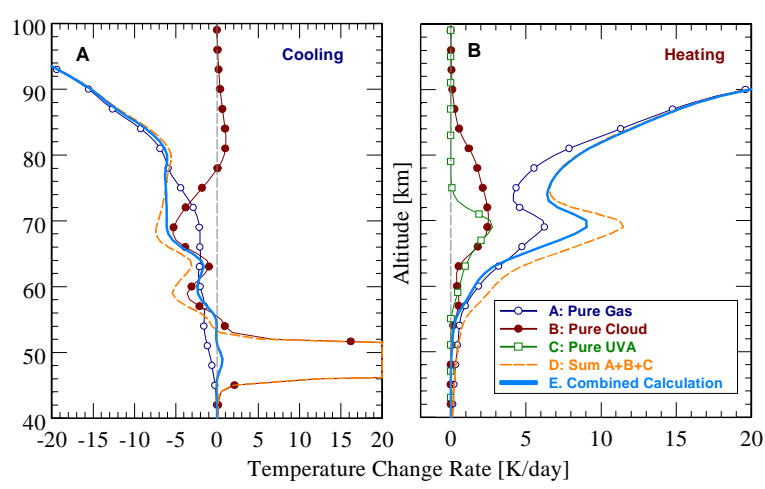

Fig. 6. Contributions of individual atmospheric components to the total temperature change rates at equatorial latitudes. The components are not additive.

Unfortunately, the search for suitable parameterization approaches is strongly hampered by the fact that temperature and cloud influences on radiative temperature change rates are not additive. This is illustrated in Fig. 6 where thermal cooling rates (display $\mathrm{A}$ ) and solar heating rates (display B) at the equator are compared for different modeling assumptions. VIRA-1 is used as basis temperature model. Case A describes results when only gaseous 
Haus, R., et al., ICARUS 284, 216-232 (2017)

absorption and scattering is considered, cases $\mathrm{B}$ and $\mathrm{C}$ characterize pure cloud and pure UVA absorption and scattering conditions. The broken lines in each display (case D) result from summing up the three components. It is obvious that these profiles strongly differ from case $\mathrm{E}$ where all components are considered together in the calculation procedure. Real world Q profiles provide less cooling or heating at altitudes below $75 \mathrm{~km}$. A dramatic example on how separate calculations may distort the results is discernible in case of cooling near the cloud base $(\sim 48 \mathrm{~km})$. Neglect of gaseous absorptions produces a cloud base thermal heating that is far away from reality and reaches $150 \mathrm{~K} /$ day.

Thus, it becomes clear that separate parameterization approaches for temperature and cloud / UVA influences are somewhat puzzling. A parameterization based on changing temperature (T) profiles would not work from the outset without considering appropriate cloud parameters. It must not be limited to pure gas, cloud, or UVA cases. In other words, any $\mathrm{T}$ parameterization has to be performed as function of latitude considering latitude-specific cloud parameters (individual mode abundance factors, scale heights, cloud top altitude) and relying on a pre-specified standard cloud model (chemical cloud composition, individual initial mode altitude distributions and particle number densities). This resembles a Taylor expansion centered at an evaluation point as close as possible to the expected target values. Solar heating rates $\mathrm{Q}^{\mathrm{H}}$ additionally strongly depend on the variation of insolation with latitude, and tests have shown that application of a simple cosine-law to characterize latitude-dependent heating does not work.

There is another difficulty mainly with respect to radiative thermal cooling. Fig. 7 shows zonally averaged mean thermal cooling (display A) and solar heating (display B) rates at the equator as functions of temperature perturbations $\mathrm{T}^{\mathrm{D}}$ at selected altitudes. VIRA-1 is used as basis temperature model. The response of $\mathrm{Q}^{\mathrm{C}}$ to
Doi: 10.1016/j.icarus.2016.11.025 Preprint

$\mathrm{T}^{\mathrm{D}}$ is not linear in general. This means that responses calculated for $\mathrm{T}^{\mathrm{D}}=1 \mathrm{~K}$ for example cannot be converted to responses when the temperature perturbation is ten or twenty times larger or smaller by simply multiplying the results for $\mathrm{T}^{\mathrm{D}}=1 \mathrm{~K}$ by these factors. This is well confirmed by the thick broken line in display A for the $85 \mathrm{~km}$ level where such scaling is illustrated. Scaling may work for perturbations up to $4-5 \mathrm{~K}$ but definitely fails for $\mathrm{T}^{\mathrm{D}}$ beyond $\pm 5 \mathrm{~K}$. The non-linearity effect decreases with decreasing altitude but occurs at all altitudes. As a consequence, parameterization of $\mathrm{Q}^{\mathrm{C}}$ requires temperature perturbation calculations for a broad range of $\mathrm{T}^{\mathrm{D}}$ values. A range of $\pm 35 \mathrm{~K}$ is usually adequate to consider observed temperature variations in the atmosphere of Venus. Nevertheless, the lower range was extended down to $-100 \mathrm{~K}$ for other applications (cf. Section 5).

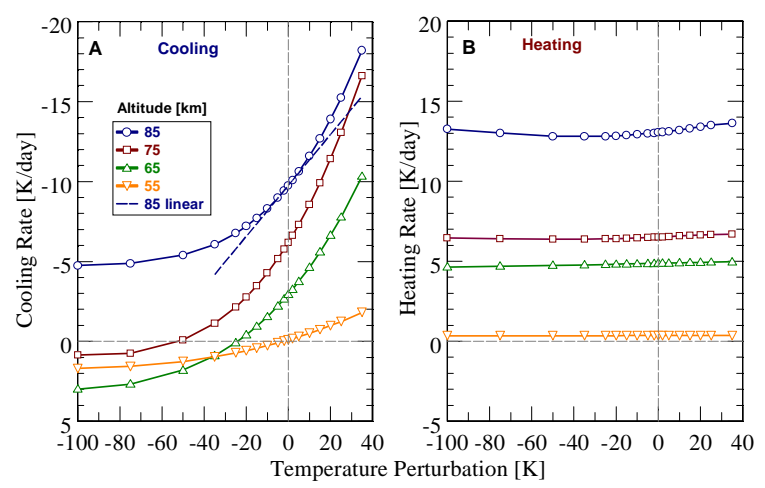

Fig. 7. Zonally averaged mean thermal cooling (A) and solar heating $(\mathrm{B})$ rates at the equator as functions of temperature perturbations $\mathrm{T}^{\mathrm{D}}$ at selected altitudes.

In contrast with $\mathrm{Q}^{\mathrm{C}}$, the heating rate $\mathrm{Q}^{\mathrm{H}}$ dependence on $\mathrm{T}^{\mathrm{D}}$ is almost linear except of perturbations exceeding $-20 \mathrm{~K}$ at altitudes above about $80-85 \mathrm{~km}$. Thus, it is sufficient to consider $\mathrm{T}^{\mathrm{D}}$ values of $\pm 15,+35,-50$, and $100 \mathrm{~K}$ assuming almost linear conditions between two adjacent values.

The proposed parameterization algorithm to calculate altitude profiles of atmospheric temperature change rates proceeds in the following seven steps.

Step 1

In the first step, accurate calculations of perturbed $Q$ fields $\mathrm{Q}\left(\mathrm{T}^{\mathrm{P}}{ }_{\mathrm{kj}}\left(\mathrm{Z}_{\mathrm{i}}, \varphi_{\mathrm{n}}\right)\right)$ are performed. $\mathrm{T}^{\mathrm{P}}{ }_{\mathrm{kj}}\left(\mathrm{Z}_{\mathrm{i}}, \varphi_{\mathrm{n}}\right)$ is the perturbed 
temperature profile that everywhere coincides with $\mathrm{T}^{0}\left(\mathrm{z}_{\mathrm{i}}, \varphi_{\mathrm{n}}\right)$ except for the altitude level $\mathrm{j}$ where it attains $\mathrm{T}^{0}\left(\mathrm{z}_{\mathrm{j}}, \varphi_{\mathrm{n}}\right)+$ $T^{D}{ }_{k}\left(z_{j}\right)$. Index $k$ denotes one of the specific $\mathrm{T}^{\mathrm{D}}$ values as discussed above. $\mathrm{T}^{0}$ is the basis latitude-dependent temperature model (VIRA-1 is selected here) at each of the 119 altitude levels $z_{i}$ where $Q$ values are generally calculated starting at the top of atmosphere (TOA, $\mathrm{z}_{1}=140 \mathrm{~km}$ ) and moving down to $\mathrm{z}_{119}=0 \mathrm{~km}$ using different altitude steps $(\Delta \mathrm{z}=1 \mathrm{~km}: 0-5 \mathrm{~km}$ and $40-130 \mathrm{~km}$, $\Delta \mathrm{z}=2 \mathrm{~km}: \quad 6-38 \mathrm{~km}$ and $132-140 \mathrm{~km})$. Numerous test calculations have revealed that it is sufficient to consider $\mathrm{Z}_{\mathrm{j}}$ levels between $110 \mathrm{~km}(\mathrm{j}=26)$ and $30 \mathrm{~km}(\mathrm{j}=101)$ in case of cooling and levels between $110 \mathrm{~km}$ and $55 \mathrm{~km}(\mathrm{j}=81)$ in case of heating. This is due to the facts that mesospheric calculations are limited to altitudes below $100 \mathrm{~km}$, and $\mathrm{Q}^{\mathrm{C}}$ and $\mathrm{Q}^{\mathrm{H}}$ are almost insensitive to temperature changes below the given levels. The calculation of cooling fields $\mathrm{Q}^{\mathrm{C}}$ includes $18 \mathrm{~T}_{\mathrm{k}}^{\mathrm{D}}$ values $( \pm 2, \pm 5, \pm 10, \pm 15, \pm 20, \pm 25$, $\pm 35,-50,-75,-100 \mathrm{~K}$, and $0 \mathrm{~K}(\mathrm{k}=18)$ as reference), while $\mathrm{Q}^{\mathrm{H}}$ fields contain 6 values (the five ones mentioned above plus $0 \mathrm{~K}$ as reference). The reference cooling/heating profiles are the profiles without any temperature perturbation and are denoted as $\mathrm{Q}_{0}\left(\mathrm{z}_{\mathrm{i}}, \varphi_{\mathrm{n}}\right)$ in the following. $\varphi_{\mathrm{n}}$ are the 19 latitudes (step $5^{\circ}$ from $0^{\circ}$ to $90^{\circ}$ ) where $\mathrm{Q}$ is calculated for. The $90^{\circ}$ value is substituted by $89^{\circ}$ to avoid zero heating.

This first step of the parameterization approach requires huge amounts of processing time on current computer hardware. For one $\mathrm{T}^{\mathrm{D}}$ value and 19 latitudes, it takes about $10 \mathrm{~h}$ in case of cooling and about $50 \mathrm{~h}$ in case of heating even when a coarse wavenumber grid ('point distance' $\mathrm{PD}$ for $\mathrm{Q}^{\mathrm{C}}: 1 \mathrm{~cm}^{-1}$, PD for $\mathrm{Q}^{\mathrm{H}}: 10 \mathrm{~cm}^{-1}$ ) is used in the quasi-monochromatic flux and temperature change rate calculations. Heating rate calculations are more expensive due to a much broader spectral range and due to the required integration over solar zenith angle. Fortunately, it turned out that spectral integration results that are based on the mentioned coarse wavenumber grids can be successfully corrected at the end of the parameterization procedure to reflect the spectral grid conditions used to calculate accurate cooling and heating rate profiles.

Step 2

The second step of the algorithm calculates matrices $\mathrm{M}_{\mathrm{k}}{ }^{\mathrm{C}}$ and $\mathrm{M}_{\mathrm{k}}{ }^{\mathrm{H}}$ with entries at indices ij in the form

$$
\begin{aligned}
\left(\mathrm{M}_{\mathrm{k}}\right)_{\mathrm{ij}} & =\Delta \mathrm{Q}\left(\mathrm{T}^{\mathrm{P}}{ }_{\mathrm{kj}}\left(\mathrm{z}_{\mathrm{i}}, \varphi_{\mathrm{n}}\right)\right) \\
& =\mathrm{Q}\left(\mathrm{T}^{\mathrm{P}}{ }_{\mathrm{kj}}\left(\mathrm{z}_{\mathrm{i}}, \varphi_{\mathrm{n}}\right)\right)-\mathrm{Q}_{0}\left(\mathrm{z}_{\mathrm{i}}, \varphi_{\mathrm{n}}\right)
\end{aligned} .
$$

The meaning of $\mathrm{Q}$ and $\mathrm{Q}_{0}$ was explained above. Fig. 8 illustrates $\mathrm{M}_{\mathrm{k}}{ }^{\mathrm{C}}$ (display A) and $\mathrm{M}_{\mathrm{k}}{ }^{\mathrm{H}}$ (display $\mathrm{B}$ ) results, that is, temperature change rate responses at the equator for a temperature perturbation of the VIRA-1 profile of $+10 \mathrm{~K}$ considering $\mathrm{PD}=0.1 \mathrm{~cm}^{-1}$ in case of $\mathrm{M}_{\mathrm{k}}{ }^{\mathrm{C}}$ and $\mathrm{PD}=1.0 \mathrm{~cm}^{-1}$ in case of $\mathrm{M}_{\mathrm{k}}{ }^{\mathrm{H}}$ in this plot. Different colors have no special meaning here. $\mathrm{M}_{\mathrm{k}}$ curves at $\mathrm{z}_{\mathrm{j}}$ levels of 100 , $90,80,70,60$, and $50 \mathrm{~km}$ are highlighted by thick lines. It is interesting to observe that the temperature perturbation at level $\mathrm{z}_{\mathrm{j}}$ produces a strong response at level $z_{i}$ for $\mathrm{i}=\mathrm{j}$

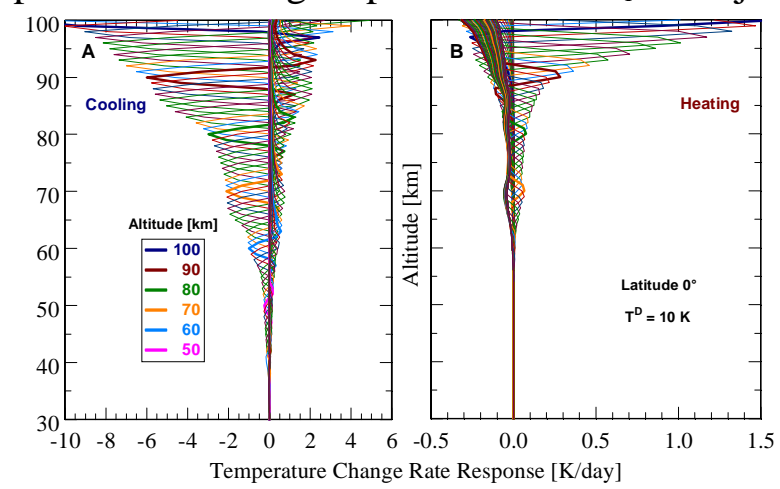

Fig. 8. Illustration of matrices $M_{k}$ according to Eq. (2).

(as expected) but additional responses at levels $\mathrm{z}_{\mathrm{i}}>\mathrm{z}_{\mathrm{j}}$ and $\mathrm{z}_{\mathrm{i}}<\mathrm{z}_{\mathrm{j}}$, respectively. These additional responses are usually characterized by a 'swinging' that leads to opposite effects peaking at about $2-3 \mathrm{~km}$ away from the actual perturbation level $\mathrm{z}_{\mathrm{j}}$. It was thoroughly checked whether or not a change of vertical resolution in both accurate and parameterization calculations may cause a failure of the parameterization approach. Apart from the fact that a lower vertical resolution may generally smooth out some features seen for the above described standard altitude grid, the agreement of results for the two calculation methods is always as good as for the standard grid (as 
shown for the latter in Section 3.2 below). The observed 'swinging' appears for each situation.

Temperature perturbations below $40 \mathrm{~km}$ in case of cooling and below $60 \mathrm{~km}$ in case of heating only marginally influence the temperature change rates. This is the reason why perturbation calculations can be aborted at lower altitude bounds of $30 \mathrm{~km}(\mathrm{j}=101)$ and $55 \mathrm{~km}(\mathrm{j}=81)$, respectively, as already mentioned above. Fig. 8 also confirms that the response of atmospheric heating rates to a changing thermal structure is rather weak compared with cooling rate responses. Note the different abscissa scales.

The final matrices used in the parameterization procedure may slightly differ at altitudes above $78 \mathrm{~km}$. First, due to the coarser wavenumber grid used for operational calculations as discussed above, and second, due to a smoothing procedure applied to thermal net flux divergences above $80 \mathrm{~km}$ to avoid unphysical fluctuations of cooling rate profiles in this altitude domain. The smoothing changes the $\mathrm{M}_{\mathrm{k}}{ }^{\mathrm{C}}$ shapes at altitudes between 78 and 82 $\mathrm{km}$ and reduces the response strength at altitudes above $82 \mathrm{~km}$, while the shapes below $78 \mathrm{~km}$ remain unchanged. Since the smoothing procedure is always applied even in case when accurate $\mathrm{Q}^{\mathrm{C}}$ profiles are calculated, this change of matrices does not alter the differences between accurate and parameterization results, that is, the usefulness and quality of the proposed method do not suffer from these modifications.

\section{Steps 3-6}

Step three of the parameterization approach determines actual temperature differences comparing the target temperature profile and the basis one. VIRA-1 is always used as basis model, while the target model is freely selectable within reasonable limits.

$$
\begin{aligned}
& \Delta \mathrm{T}^{\text {TARGET }}\left(\mathrm{z}_{\mathrm{i}}, \varphi_{\mathrm{n}}\right)= \\
& \mathrm{T}^{\text {TARGET }}\left(\mathrm{z}_{\mathrm{i}}, \varphi_{\mathrm{n}}\right)-\mathrm{T}^{\text {VIRA-1 }}\left(\mathrm{z}_{\mathrm{i}}, \varphi_{\mathrm{n}}\right)
\end{aligned} .
$$

The fourth step performs a linear interpolation of $\mathrm{M}_{\mathrm{k}}{ }^{\mathrm{C}}$ and $\mathrm{M}_{\mathrm{k}}{ }^{\mathrm{H}}$ matrices calculated for different values of $\mathrm{T}^{\mathrm{D}}$ to the actual temperature conditions determined by Eq. (3), resulting in only one matrix for cooling and heating, respectively, denoted as $M^{\text {TARGET }}\left(z_{i}, \quad \varphi_{n}, \quad \Delta T^{\text {TARGET }}\left(z_{j}\right)\right)$. These matrices are summed up over level $\mathrm{j}$ in the fifth step,

$$
\begin{aligned}
& \operatorname{MS}^{\text {TARGET }}\left(\mathrm{z}_{\mathrm{i}}, \varphi_{\mathrm{n}}\right)= \\
& \sum_{\mathrm{j}} \mathrm{M}^{\text {TARGET }}\left(\mathrm{z}_{\mathrm{i}}, \varphi_{\mathrm{n}}, \Delta \mathrm{T}^{\text {TARGET }}\left(\mathrm{z}_{\mathrm{j}}\right)\right)
\end{aligned}
$$

Step six determines actual cooling and heating rates for the target temperature profile using the relation

$$
\begin{aligned}
& \mathrm{Q}^{\text {TARGET }}\left(\mathrm{z}_{\mathrm{i}}, \varphi_{\mathrm{n}}\right)= \\
& \mathrm{Q}_{0}\left(\mathrm{z}_{\mathrm{i}}, \varphi_{\mathrm{n}}\right)+\mathrm{MS}^{\text {TARGET }}\left(\mathrm{z}_{\mathrm{i}}, \varphi_{\mathrm{n}}\right)
\end{aligned} .
$$

\section{Step 7}

It was mentioned above that the timeconsuming calculation of $\mathrm{Q}$ fields in step 1 utilizes a rather coarse wavenumber grid especially in case of solar heating. The seventh and last step of the temperature parameterization algorithm therefore corrects the results from Eq. (5) applying wavenumber grid correction factors $\alpha^{\mathrm{C}}$ and $\alpha^{\mathrm{H}}$. They are determined from accurate $Q^{\mathrm{C}}$ and $\mathrm{Q}^{\mathrm{H}}$ calculations for VIRA-1 temperature profiles using the wavenumber range dependent fine wavenumber grids (point distances PD) that were characterized by Haus et al. (2015b) as the 'optimum grids'. It was carefully checked here that the used basis temperature model does not significantly change these factors. They are calculated according to

$$
\begin{aligned}
& \alpha\left(\mathrm{z}_{\mathrm{i}}, \varphi_{\mathrm{n}}\right)= \\
& \mathrm{Q}_{0}{ }^{\text {accurate }}\left(\mathrm{z}_{\mathrm{i}}, \varphi_{\mathrm{n}}\right) / \mathrm{Q}_{0}{ }^{\text {coarse }}\left(\mathrm{z}_{\mathrm{i}}, \varphi_{\mathrm{n}}\right)
\end{aligned}
$$

The final $\mathrm{Q}^{\mathrm{C}}$ and $\mathrm{Q}^{\mathrm{H}}$ fields are then obtained from Eq. (7),

$$
\begin{aligned}
& \mathrm{Q}^{\text {TARGET-cor }}\left(\mathrm{z}_{\mathrm{i}}, \varphi_{\mathrm{n}}\right)= \\
& \mathrm{Q}^{\text {TARGET }}\left(\mathrm{z}_{\mathrm{i}}, \varphi_{\mathrm{n}}\right) * \alpha\left(\mathrm{z}_{\mathrm{i}}, \varphi_{\mathrm{n}}\right)
\end{aligned} .
$$

Table A1 in the appendix lists the used initial (or basis) temperature model $\left(\mathrm{T}^{\mathrm{VIRA}-1}\left(\mathrm{z}_{\mathrm{i}}, \varphi_{\mathrm{n}}\right)\right)$ at altitudes between 100 and $40 \mathrm{~km}$ at four selected latitudes and resulting initial (accurate) cooling and heating rates $\mathrm{Q}_{0}{ }^{\text {accurate }}\left(\mathrm{z}_{\mathrm{i}}, \varphi_{\mathrm{n}}\right)$. 


\subsection{Results}

Fig. 9 shows a comparison of zonally averaged mean cooling rate results obtained from accurate and parameterization calculations, respectively. VIRA-1 is the basis temperature model, VIRTIS temperatures as retrieved from VEX measurements are the target model. Latitudes of $20^{\circ}$ (display A) and $80^{\circ}$ (display B) are selected. Broken lines result from use of Eq. (5) where the PD correction is not yet applied. The agreement between the two curves marked by empty and solid symbols in each case is very good indicating that the parameterization approach described in Section 3.1 is working very well despite the partly large $\mathrm{Q}^{\mathrm{C}}$ differences between basis and target model. Accurate calculations of the 2D cooling rate field for a certain temperature model require about 2 hours, while the parameterization approach using the pre-calculated $\mathrm{M}_{\mathrm{k}}{ }^{\mathrm{C}}$ matrix takes only 3 seconds. The gain of processing time becomes much more dramatic in case of heating rates where a full accurate run requires more than 10 hours compared with again 3 seconds for the parameterization case.

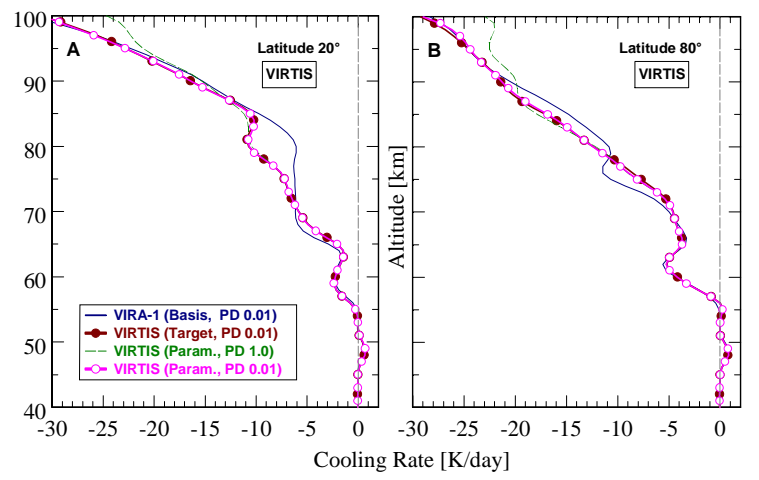

Fig. 9. Comparison of zonally averaged mean thermal cooling rates obtained from accurate and parameterization (Param.) calculations, respectively. PD is the used point distance $\left[\mathrm{cm}^{-1}\right]$. A: VIRTIS, latitude $20^{\circ}$, B: VIRTIS, latitude $80^{\circ}$.

By analogy with Fig. 9, Fig. 10 shows the comparison of zonally averaged mean cooling rate results when VeRa temperature profiles as retrieved from VEX measurements are the target model. The agreement between the two curves marked by empty and solid symbols in each case (display A for latitude $45^{\circ}$, display $\mathrm{B}$ for latitude $65^{\circ}$ ) is very good again. Fig. 11 illustrates the comparison of zonally averaged mean heating rate results when VIRTIS (display A) and VeRa (display B) temperature profiles at two example latitudes are selected as target. Due to the weak temperature dependence of solar heating rates, the agreement between accurate and parameterization calculations is almost perfect below $90 \mathrm{~km}$ in all cases.

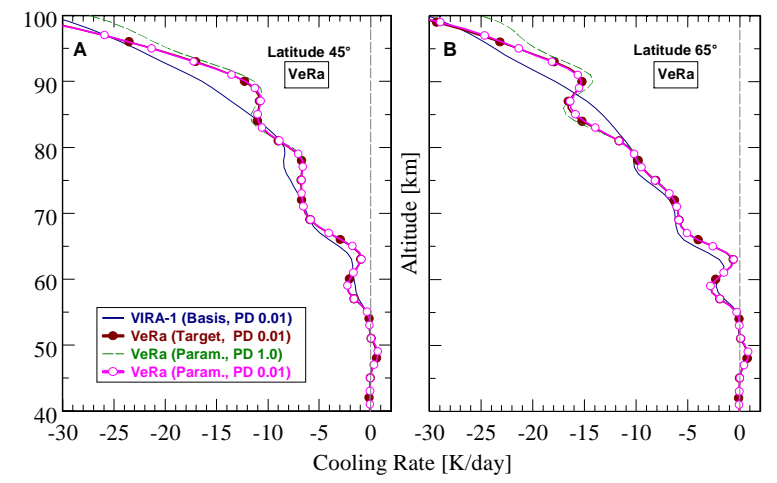

Fig. 10. Same as Fig. 9 but A: VeRa, latitude $45^{\circ}$, B: VeRa, latitude $65^{\circ}$.

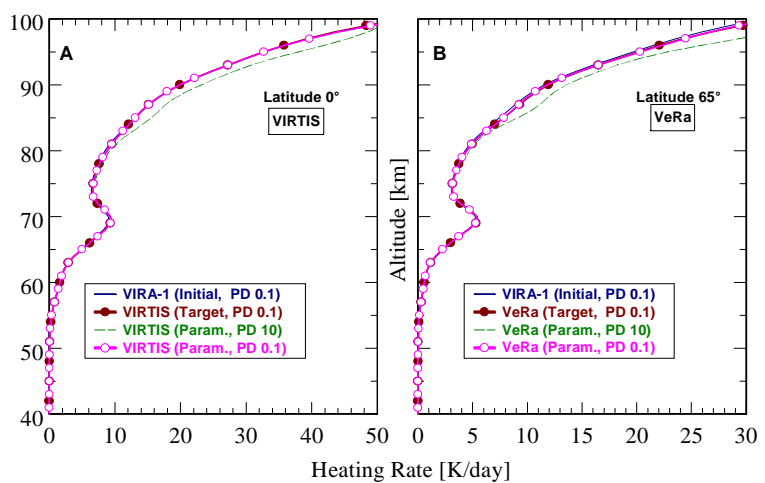

Fig. 11. Comparison of zonally averaged mean solar heating rates obtained from accurate and parameterization (Param.) calculations, respectively. $\mathrm{PD}$ is the used point distance $\left[\mathrm{cm}^{-1}\right]$. A: VIRTIS, latitude $0^{\circ}, \mathrm{B}$ : VeRa, latitude $65^{\circ}$.

Fig. 12 illustrates thermal cooling rate differences as functions of latitude and altitude when parameterization (set 1) and accurate calculation (set 2) results are compared, $\Delta \mathrm{Q}^{\mathrm{C}}($ set 1 , set 2$)=\mathrm{Q}^{\mathrm{C}}($ set 1$)$ $\mathrm{Q}^{\mathrm{C}}$ (set 2). Positive values characterize weaker set 1 cooling. Displays A-C refer to VIRTIS, VeRa, and VIRA-2 temperature models. Display D describes the case where the VIRA-1 model was modified by $+10 \mathrm{~K}$ between 50 and $100 \mathrm{~km}$. As it can already be expected from Figs. 9 and 10, cooling rate deviations below $70 \mathrm{~km}$ and for cases A-C do not exceed $\pm 0.1 \mathrm{~K} /$ day. Between 70 and $90 \mathrm{~km}$, they sometimes reach $\pm(0.2-0.3)$ 
K/day at high latitudes (i.e., about $1 \%$ ). Maximum deviations in the order of +0.5 $\mathrm{K} /$ day are observed near $100 \mathrm{~km}$ and $60^{\circ}$ in case of VIRTIS. Deviations above $70 \mathrm{~km}$ in display $\mathrm{D}$ are generally larger compared with A-C, but they do rarely exceed $-1 \mathrm{~K} /$ day. This means that case D cooling obtained from the parameterization at altitudes between 70 and $100 \mathrm{~km}$ may be up to 1 $\mathrm{K} /$ day stronger compared with accurate results. The larger differences indicate that the parameterization approach seems to work best in cases where the target temperature profiles multiply intersect the basis profile as it happens for cases A-C (cf. Figs. 1A and 1B). This keeps the magnitude of perturbations relatively small. 2D solar heating rate differences are not shown here. They are less than $\pm 0.01 \mathrm{~K} /$ day below $70 \mathrm{~km}$ and do not exceed $\pm 0.1 \mathrm{~K} /$ day up to $90 \mathrm{~km}$. Larger deviations up to $\pm 1 \mathrm{~K} /$ day may occur at $100 \mathrm{~km}$.

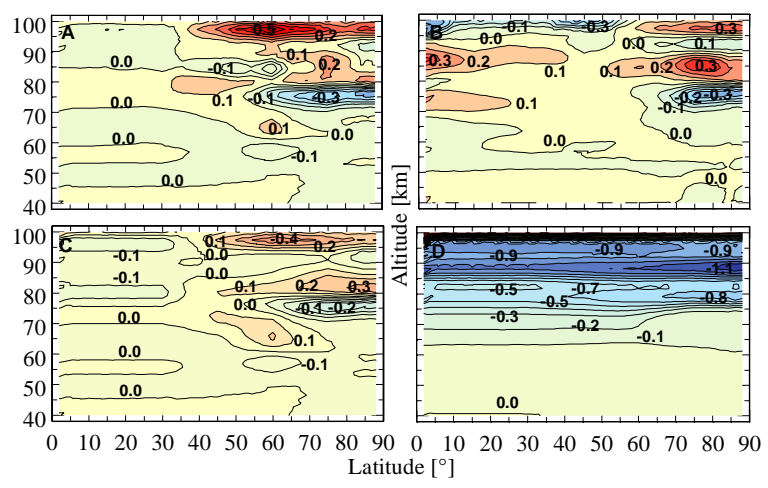

Fig. 12. Differences $\Delta Q^{C}[K /$ day $]$ of zonally averaged mean thermal cooling rates as functions of latitude and altitude when parameterization and accurate calculations are compared. A: VIRTIS, B: VeRa, C: VIRA-2, D: VIRA-1 +10 K between 50 and $100 \mathrm{~km}$.

All in all, these results are very satisfying. Taking into account the sensitivity analyses of temperature change rates with respect to spectroscopic and atmospheric parameter influences performed by Haus et al. (2015b) and considering the fact that parameter retrieval results obtained at regions close to measurement sensitivity bounds are especially prone to possible errors, it was stated by Haus et al. (2016) that calculated temperature change rates at altitudes above $90 \mathrm{~km}$ are less reliable than for lower altitudes. Increasing parameterization errors at these altitudes do not disparage the success of the proposed method, therefore.

\section{Parameterization of temperature change rates as functions of cloud parameters and UVA abundance}

It was already outlined in Section 3.1 that separate parameterization approaches for temperature and cloud / UVA influences are very difficult to accomplish, since responses of temperature change rates to the different parameters are not additive (cf. Fig. 6). Temperature parameterizations described so far rely on a pre-specified standard cloud model $\left(75 \mathrm{wt} \% \mathrm{H}_{2} \mathrm{SO}_{4}\right.$, initial mode altitude distributions and particle number densities according to Table 1). They also consider latitude-specific cloud parameters (changing scale heights and individual mode abundance factors according to Tables 2 and 3).

Nevertheless, it should be possible to subsequently include cloud and UVA correction steps into the overall parameterization approach that consider possible changes of cloud mode factors $\mathrm{MF}_{1,2}$ and $\mathrm{MF}_{3}$ and abundance of the unknown UV absorber. This would allow GCMs to consider changing cloud and UVA opacities. The proposed method is described below.

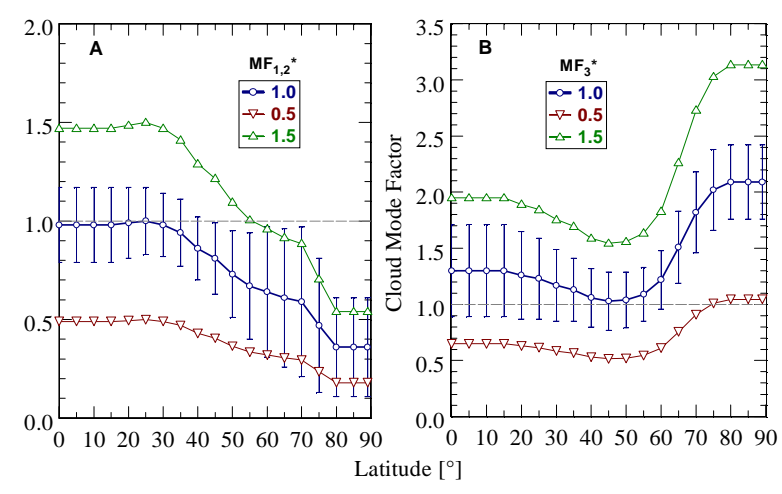

Fig. 13. Latitude dependence of mean cloud mode factors $\left(\mathrm{A}: \mathrm{MF}_{1,2}{ }^{*}, \mathrm{~B}: \mathrm{MF}_{3}{ }^{*}\right)$ and their standard deviations $\sigma_{\mathrm{MFi}}$ as retrieved from VIRTIS-M-IR measurements and additional modification of mean values by $\pm 50 \%$.

Fig. 13 visualizes the latitude-dependent mean cloud mode factors $\mathrm{MF}_{1,2}{ }^{*}$ (display $\mathrm{A}$ ) and $\mathrm{MF}_{3}{ }^{*}$ (display $\mathrm{B}$ ) given in Table 3 together with retrieved single standard deviations $\sigma_{\mathrm{MFi}}$ that describe observed real variations (Haus et al., 2016). The additional two curves depict the cases when the mean 
retrieval results are generally reduced or enhanced by $50 \%$, that is, applying additional (latitude-independent) cloud mode factors $\mathrm{MF}_{\mathrm{i}}{ }^{*}$ of 0.5 and 1.5 , respectively. These factors are quite representative over broad latitude ranges to cover observed variations even when larger variances (e.g. $\left.2 \sigma_{\mathrm{MFi}}\right)$ are considered. The superscript asterisk indicates that these factors are additionally employed to the factors given in Table 3 (that is, for $\mathrm{MF}_{\mathrm{i}}{ }^{*}=1.0$ ).

Thermal cooling rates $\mathrm{Q}^{\mathrm{C}}$ strongly respond to temperature profile changes, and it can be expected that their response to additional cloud parameter changes is different for each temperature model. This is illustrated in Fig. $\underline{14}$ where cooling rate differences $\Delta \mathrm{Q}^{\mathrm{C}}$ (set 1 , set 2) $=\mathrm{Q}^{\mathrm{C}}$ (set 1) - $\mathrm{Q}^{\mathrm{C}}$ (set 2) are shown as functions of latitude and altitude and for the four temperature models VIRTIS (display A), VeRa (B), VIRA-2 (C), and VIRA-1 (D). Sets 1 and 2 correspond to $\mathrm{MF}_{1,2}{ }^{*}=1.5$ and 1.0, respectively, and the notation $\mathrm{Y}^{\mathrm{C}-}$ ${ }^{\mathrm{T}}\left(\mathrm{MF}_{1,2}{ }^{*}\right)$ is introduced here instead of $\Delta \mathrm{Q}^{\mathrm{C}}$ (set 1, set 2). Superscript $\mathrm{T}$ refers to one of the individual temperature fields. Positive values in Fig. 14 characterize weaker set 1 cooling. This means that increasing $\mathrm{MF}_{12}{ }^{*}$ values produce more cooling at altitudes above about $65 \mathrm{~km}$ but less cooling at lower altitudes.

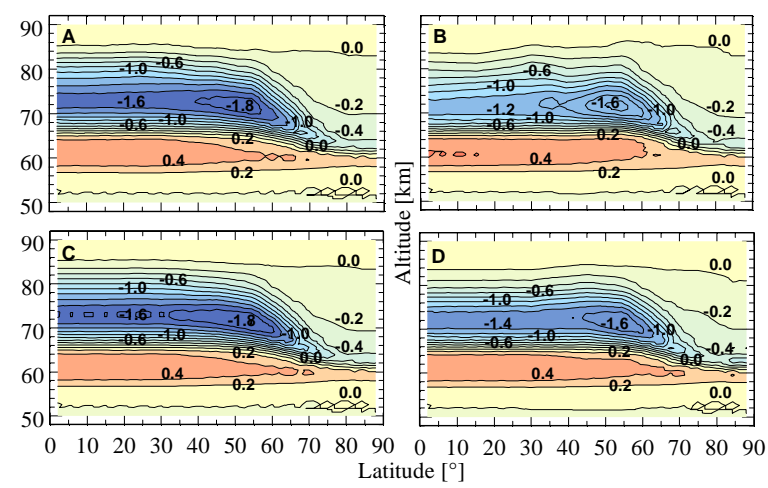

Fig. 14. Cooling rate changes [K/day] due to cloud mode factor $\mathrm{MF}_{1,2}{ }^{*}$ increase by $50 \%$ using different temperature models (A: VIRTIS, B: VeRa, C: VIRA2, D: VIRA-1).

When Fig. 14 is compared with Fig. 4, there seems to be a contradiction at first sight. Fig. 4A shows large mode factor influences at high latitudes, while low latitudes are almost unaffected. Fig. 14 shows a reversed trend. But this is due to different data sets that are compared in the two figures. Fig. 4A illustrates differences of $Q^{C}$ fields when latitudinal variations of cloud parameters (not only variations of mode factors but also changes of mode 2 altitude distribution and cloud top altitudes) are considered or neglected. Fig. 13A reveals that retrieved $\mathrm{MF}_{1,2}$ values remain almost constant at low latitudes and approach the value $\mathrm{MF}_{1,2}=1.0$. Poleward of $30^{\circ}, \mathrm{MF}_{1,2}$ decreases with increasing latitude reaching values near 0.5 at about $75^{\circ}$. As a consequence, cooling rates at high latitudes strongly decrease at altitudes above about $65 \mathrm{~km}$ leading to positive differences $\Delta \mathrm{Q}$ (set 1 , set 2) where set 1 and set 2 denote actually retrieved and latitude-independent model cloud parameter conditions. In contrast with Fig. 4A, Fig. 14 relies on the retrieved latitudinal behavior of cloud mode parameters (e.g. using data from Tables 2 and 3) but describes $\mathrm{Q}^{\mathrm{C}}$ changes due to the additionally applied mode factor $\mathrm{MF}_{1,2}{ }^{*}=1.5$. According to Fig. $13 \mathrm{~A}$ this means that final mode factors of about 1.5 are considered at low latitudes resulting in stronger cooling compared with Fig. 4A. At high latitudes, especially poleward of $70^{\circ}$, reduced $\mathrm{MF}_{1,2}$ values are now partly compensated by the additionally considered $\mathrm{MF}_{1,2}{ }^{*}=1.5$. This leads again to a cooling excess, but due to decreasing mode factor differences, high latitude $\mathrm{Q}^{\mathrm{C}}$ changes in Fig. 14 become smaller compared with low latitudes.

Although the general responses in the four temperature cases in Fig. 14 are similar, some details are different (e.g. near $80 \mathrm{~km}$ ). The four difference fields $\mathrm{Y}^{\mathrm{C}-\mathrm{T}}\left(\mathrm{MF}_{1,2}{ }^{*}\right)$ are now used to calculate an average difference field $\mathrm{Y}^{\mathrm{C}-\mathrm{AV}}\left(\mathrm{MF}_{1,2}{ }^{*}\right)$ as shown in Fig. 15 (display A). In a subsequent step, deviations $\delta$ of the individual difference fields from this average difference field are calculated in the form $\delta=\mathrm{Y}^{\mathrm{C}-\mathrm{T}}-\mathrm{Y}^{\mathrm{C}-\mathrm{AV}}$. This allows an estimate of approximate errors of cooling rate responses to $\mathrm{MF}_{1,2}{ }^{*}$ changes when this averaged data set is utilized in different temperature environments. Results are illustrated in Fig. 16. The deviations are definitely much smaller than in case of using for example VIRA-1 results (the difference 


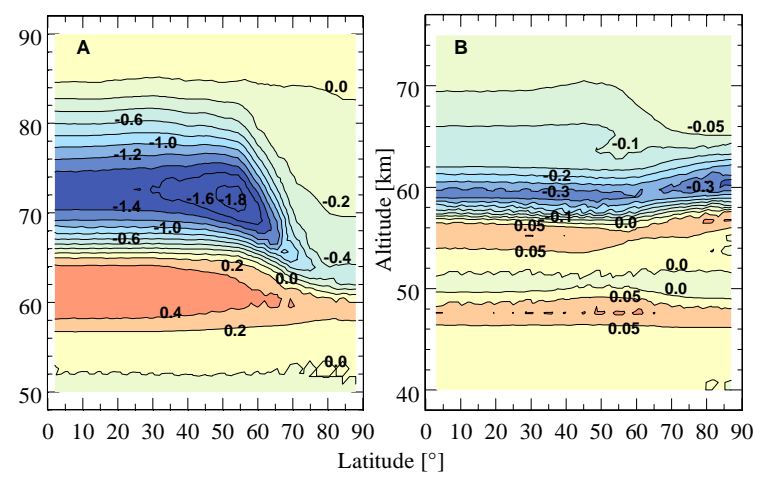

Fig. 15. Average cooling rate changes $[\mathrm{K} /$ day $]\left(\mathrm{A}\right.$ : $\mathrm{Y}^{\mathrm{C}-}$ $\left.{ }^{\mathrm{AV}}\left(\mathrm{MF}_{1,2}{ }^{*}\right), \mathrm{B}: \mathrm{Y}^{\mathrm{C}-\mathrm{AV}}\left(\mathrm{MF}_{3}{ }^{*}\right)\right)$ due to cloud mode factor increase by $50 \%$ determined from individual changes for different temperature models.
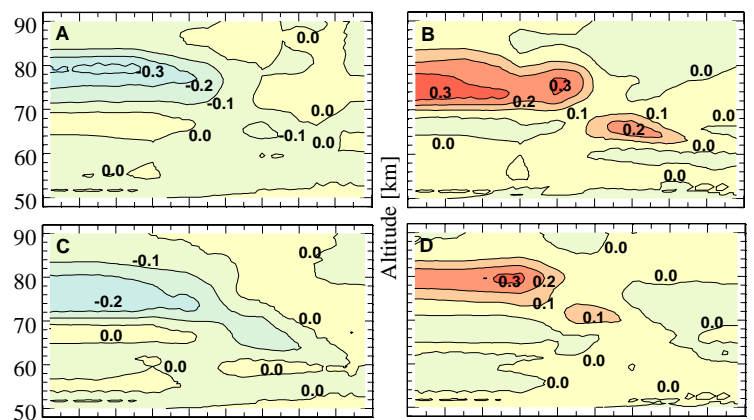

$\begin{array}{llllllllllllllllllll}0 & 10 & 20 & 30 & 40 & 50 & 60 & 70 & 80 & 90 & 0 & 10 & 20 & 30 & 40 & 50 & 60 & 70 & 80 & 90\end{array}$ Latitude $\left[{ }^{\circ}\right]$

Fig. 16. Deviations of individual cooling rate difference fields [K/day] due to $\mathrm{MF}_{1,2}{ }^{*}$ increase by $50 \%$ from the average difference field. (A: VIRTIS, B: VeRa, C: VIRA-2, D: VIRA-1).

field $\left.\mathrm{Y}^{\mathrm{C}-\mathrm{VIRA}-1}\left(\mathrm{MF}_{1,2}{ }^{*}\right)\right)$ to model cloud parameter influences for the temperature environment determined by VIRTIS. Below $70 \mathrm{~km}$, cooling rate deviations (or errors $\delta$ ) rarely exceed $\pm 0.1 \mathrm{~K} /$ day and quickly further decrease with decreasing altitude. Maximum deviations in the order of $\pm 0.3 \mathrm{~K} /$ day occur between 75 and $80 \mathrm{~km}$. The errors depend approximately linearly on the mode factor change. An increase or decrease of $\mathrm{MF}_{1,2}{ }^{*}$ by $10 \%$ compared with nominal conditions would produce maximum $\mathrm{Q}^{\mathrm{C}}$ parameterization errors of $\pm 0.06 \mathrm{~K} /$ day. Even in case of $50 \%$ or higher mode factor changes, the drawbacks of these errors can be tolerated considering the much smaller required computer resources compared with accurate calculations. Note that the average difference field $\mathrm{Y}^{\mathrm{C}-\mathrm{AV}}$ as the arithmetical mean of the four individual difference fields $\mathrm{Y}^{\mathrm{C}-\mathrm{T}}$ for VIRTIS, VeRa, VIRA-2, and VIRA1 temperature environments does not provide 'absolute truth' information. It may change when other temperature models are considered. But these four models are regarded to represent reliable data sets that describe the thermal structure of Venus' mesosphere and troposphere according to present knowledge.

By analogy with Fig. $15 \mathrm{~A}$, the average $\mathrm{Y}^{\mathrm{C}-}$ ${ }^{\mathrm{AV}}\left(\mathrm{MF}_{3}{ }^{*}\right)$ for cloud mode factor $\mathrm{MF}_{3}{ }^{*}=1.5$ is depicted in Fig. 15B. The difference in the ordinate scale considers the fact that mode 3 influences only occur at altitudes below about $70 \mathrm{~km}$. As in case of $\mathrm{MF}_{1,2}{ }^{*}$ increase, increasing $\mathrm{MF}_{3}{ }^{*}$ factors produce more cooling at higher and less cooling at lower altitudes. The 'response switch' altitude in case of $\mathrm{MF}_{3}{ }^{*}$ is located around $56-57 \mathrm{~km}$ compared with $65 \mathrm{~km}$ for $\mathrm{MF}_{1,2}{ }^{*}$. It slightly increases at high latitudes, while it decreases poleward of about $55^{\circ}$ for $\mathrm{MF}_{1,2}{ }^{*}$. Deviations of the four temperature model cases from the average condition for $\mathrm{MF}_{3}{ }^{*}=1.5$ (the errors $\delta$ by analogy with Fig. 16) are not shown here. Maximum $\mathrm{Q}^{\mathrm{C}}$ errors $\delta$ are rarely larger than $\pm 0.04 \mathrm{~K} /$ day at altitudes around $55 \mathrm{~km}$ and much smaller at other altitudes. This indicates that $\mathrm{Y}^{\mathrm{C}-\mathrm{AV}}\left(\mathrm{MF}_{3}{ }^{*}\right)$ provides a quite reliable description of $\mathrm{MF}_{3}{ }^{*}$ influences for various temperature conditions.

According to the definition of the cooling rate difference $\Delta \mathrm{Q}^{\mathrm{C}}$ (set 1 , set 2$)$, the average difference fields $\mathrm{Y}^{\mathrm{C}-\mathrm{AV}}\left(\mathrm{MF}_{1,2}{ }^{*}\right)$ and $\mathrm{Y}^{\mathrm{C}}$ ${ }^{\mathrm{AV}}\left(\mathrm{MF}_{3}{ }^{*}\right)$ can now be used to modify the parameterized temperature change rates $Q^{\mathrm{C}}$ obtained so far from Eq. (7) whenever intended or required. For this purpose, the average difference fields are calculated for a broad range of $\mathrm{MF}_{1,2}{ }^{*}$ and $\mathrm{MF}_{3}{ }^{*}$ values $(0.0$, $0.25,0.5,0.75,0.9,1.0,1.1,1.25,1.5,1.75$, 2.0). Actual conditions (e.g. $\mathrm{MF}_{1,2}{ }^{*}=0.8$ and $\mathrm{MF}_{3}{ }^{*}=1.4$ ) can be considered applying a simple linear interpolation technique. The first value (0.0) enables consideration of a hypothetical cloud free atmosphere. Thus, the final cooling rates, which now additionally consider cloud mode abundance changes, are calculated from

$$
\begin{aligned}
& \mathrm{Q}^{\mathrm{C}}\left(\mathrm{z}_{\mathrm{i}}, \varphi_{\mathrm{n}}\right)=\mathrm{Q}^{\mathrm{C}-\mathrm{TARGET}-\text { cor }}\left(\mathrm{z}_{\mathrm{i}}, \varphi_{\mathrm{n}}\right)+ \\
& \mathrm{Y}^{\mathrm{C}-\mathrm{AV}}\left(\mathrm{MF}_{1,2}{ }^{*}\right)\left(\mathrm{z}_{\mathrm{i}}, \varphi_{\mathrm{n}}\right)+\mathrm{Y}^{\mathrm{C}-\mathrm{AV}}\left(\mathrm{MF}_{3}{ }^{*}\right)\left(\mathrm{z}_{\mathrm{i}}, \varphi_{\mathrm{n}}\right) .
\end{aligned}
$$

The summation of the matrices in Eq. (8) combines results of perturbation calculations 
Haus, R., et al., ICARUS 284, 216-232 (2017)

and partly empirical approaches for a subsequent correction of the cloud parameter dependent temperature parameterization by a temperature dependent cloud parameter parameterization rather than relying on an exact mathematical solution. The practical usefulness of this method was tested for many parameter combinations as exemplarily demonstrated later on in Fig. 18. This figure also demonstrates that the general non-linearity of the $\mathrm{Q}^{\mathrm{C}}$ responses to perturbations of atmospheric parameters leads to only small errors in case of (reasonable) simultaneous perturbations of both temperature and cloud parameters. Thus, the neglect of non-linear terms is not a potential drawback of the current technique.

Solar heating rates are much less sensitive to both temperature profile changes (cf. Figs. 13) and cloud parameter changes (cf. Fig. 4) than thermal cooling rates are. $\mathrm{Q}^{\mathrm{H}}$ responses to additional cloud parameter changes via $\mathrm{MF}_{1,2}{ }^{*}$ and $\mathrm{MF}_{3}{ }^{*}$ are very similar and often identical for each temperature model. The calculation of average difference fields $\mathrm{Y}^{\mathrm{H}-}$ ${ }^{\mathrm{AV}}\left(\mathrm{MF}_{1,2}{ }^{*}\right)$ and $\mathrm{Y}^{\mathrm{H}-\mathrm{AV}}\left(\mathrm{MF}_{3}{ }^{*}\right)$ is not required, therefore, and calculations for one basis temperature model are sufficient. Eq. (8) is modified accordingly in case of solar heating. Fig. 17 shows the results obtained for $\mathrm{Y}^{\mathrm{H}-\mathrm{V} \overline{\mathrm{IRA}}-1}\left(\mathrm{MF}_{1,2}{ }^{*}=1.5\right.$ ) (display $\mathrm{A}$ ) and $\mathrm{Y}^{\mathrm{H} \text {-VIRA-1}}\left(\mathrm{MF}_{3}{ }^{*}=1.5\right) \quad$ (display $\mathrm{B}$ ) when VIRA-1 is selected as reference model. The reasons for the heating rate response differences in Fig. 4B and Fig. 17 can be explained in a similar way as it was extensively outlined above with respect to Fig. 14 and the comparison of Figs. 4A, 13A, and Fig. 14.

When Figs. 15 and 17 are compared it can be concluded once more that $\mathrm{Q}^{\mathrm{H}}$ responses to cloud parameter changes are much weaker than $\mathrm{Q}^{\mathrm{C}}$ responses. Note that maximum $\mathrm{Q}^{\mathrm{H}}$ responses to $\mathrm{MF}_{1,2}{ }^{*}$ changes occur about 5 $\mathrm{km}$ higher than maximum $\mathrm{Q}^{\mathrm{C}}$ responses. Maximum deviations between Fig. 17A and plots that use other temperature models than VIRA-1 (not shown here) are in the order of $\pm 0.02 \mathrm{~K} /$ day at equatorial latitudes near 75 $\mathrm{km}$. This confirms the above statement that
Doi: 10.1016/j.icarus.2016.11.025 Preprint

calculations of average difference fields as in case of thermal cooling are not necessary.

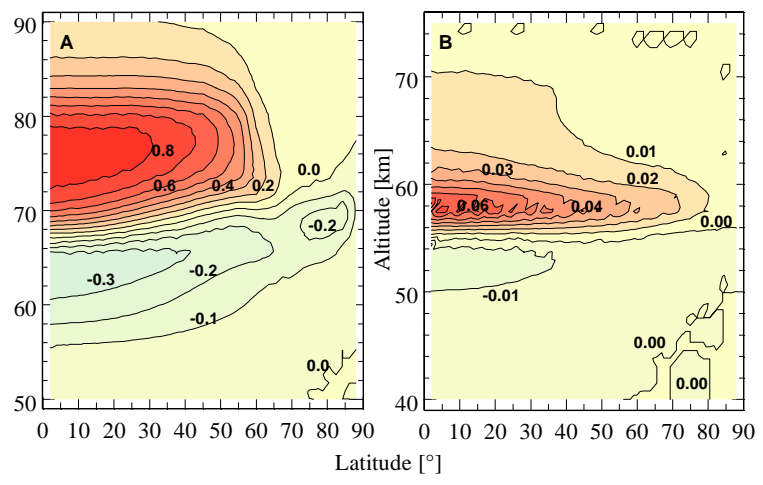

Fig. 17. Heating rate changes [K/day] (A: $\mathrm{Y}^{\mathrm{H}-\mathrm{VIRA}-}$ $\left.{ }^{1}\left(\mathrm{MF}_{1,2}{ }^{*}\right), \mathrm{B}: \mathrm{Y}^{\mathrm{H}-\mathrm{VIRA}-1}\left(\mathrm{MF}_{3}{ }^{*}\right)\right)$ due to cloud mode factor increase by $50 \%$ based on the VIRA-1 temperature model.

Solar heating rates are additionally sensitive to abundance changes of the unknown UV absorber (UVA, cf. Fig. 5). Different test calculations revealed that responses to these abundance changes are almost independent of other atmospheric parameter changes, that is, temperature models and cloud parameters that are used in the simulations. Maximum deviations in the order of $\pm 0.05 \mathrm{~K} /$ day near $70 \mathrm{~km}$ were found. As in case of cloud mode factors $\mathrm{MF}_{\mathrm{i}}$, calculations of UVA factors (UVAF) for one basis temperature model and one basis set of cloud parameters are sufficient. Eq. (8) for solar heating rates then takes the form

$$
\begin{aligned}
\mathrm{Q}^{\mathrm{H}}\left(\mathrm{z}_{\mathrm{i}}, \varphi_{\mathrm{n}}\right)= & \mathrm{Q}^{\mathrm{H}-\mathrm{TARGET}-\mathrm{cor}}\left(\mathrm{z}_{\mathrm{i}}, \varphi_{\mathrm{n}}\right)+ \\
& \mathrm{Y}^{\mathrm{H}-\mathrm{VIRA}-1}\left(\mathrm{MF}_{1,2}{ }^{*}\right)\left(\mathrm{z}_{\mathrm{i}}, \varphi_{\mathrm{n}}\right)+ \\
& \mathrm{Y}^{\mathrm{H}-\mathrm{VIRA}-1}\left(\mathrm{MF}_{3}{ }^{*}\right)\left(\mathrm{z}_{\mathrm{i}}, \varphi_{\mathrm{n}}\right)+ \\
& \mathrm{Y}^{\mathrm{H}-\mathrm{VIRA}-1}(\mathrm{UVAF})\left(\mathrm{z}_{\mathrm{i}}, \varphi_{\mathrm{n}}\right)
\end{aligned}
$$

A graph regarding $\mathrm{Q}^{\mathrm{H}}$ responses to $50 \%$ UVAF increase is not shown here. It resembles Fig. 5 where the isoline values (valid for UVAF=2.0) can be simply halved. The pre-calculated set $\mathrm{Y}^{\mathrm{H}-\mathrm{VIRA}-1}$ (UVAF) encompasses UVAF values of $0.0,0.25,0.5$, $0.75,1.0,1.25,1.5,1.75$, and 2.0 .

By analogy with Figs. 9A and 11A, Fig. 18 shows a comparison of zonally averaged mean equatorial cooling rate (display A) and heating rate (display B) results obtained from accurate and parameterization calculations, respectively. The thin solid line corresponds 
to the basis temperature model (VIRA-1) where nominal cloud and UVA parameters are used $\left(\mathrm{MF}_{1,2}{ }^{*}=1.0, \quad \mathrm{MF}_{3}^{*}=1.0\right.$, UVAF $=1.0$ ). VIRTIS temperatures as retrieved from VEX measurements are the target temperature model, and modified cloud and UVA parameters are additionally applied in this case $\left(\mathrm{MF}_{1,2} *=1.8, \mathrm{MF}_{3} *=2.0\right.$, $\mathrm{UVAF}=1.7)$. The agreement between the two curves marked by empty and solid symbols in each case is again very good. This indicates that the parameterization approach to consider both temperature and cloud / UVA changes works well.

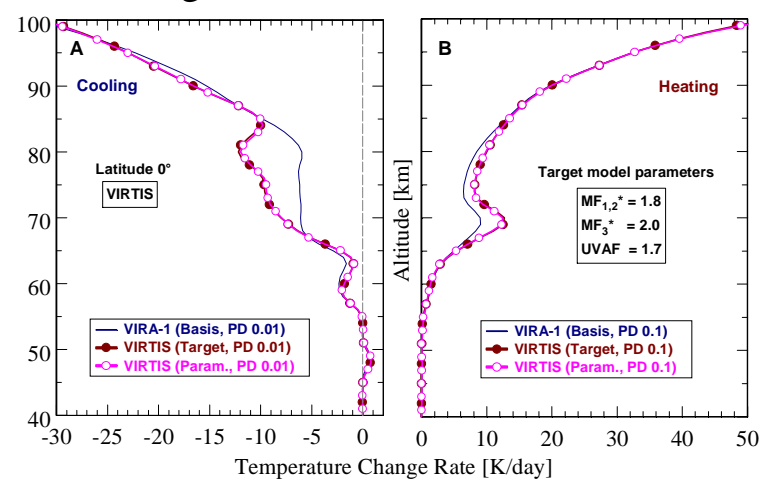

Fig. 18. Comparison of zonally averaged mean temperature change rates (A: thermal cooling, B: solar heating) obtained from accurate and parameterization (Param.) calculations, respectively. PD is the used point distance $\left[\mathrm{cm}^{-1}\right] . \mathrm{MF}_{1,2}{ }^{*}, \mathrm{MF}_{3}{ }^{*}$ : Cloud mode factors, UVAF: UV absorber abundance factor.

\section{Atmospheric radiative equilibrium conditions}

Thermal cooling and solar heating together determine the net radiative heating (radiative forcing) of the atmosphere. 2D net heating fields, that is, $\mathrm{Q}^{\mathrm{N}}$ as functions of latitude and altitude have been recently calculated by Haus et al. (2016) based on the atmospheric thermal structure as retrieved from both VIRTIS-M-IR and VeRa measurements. These results included trace gas abundance profiles and cloud parameters that were also retrieved from VIRTIS data. Cloud parameters encompassed latitude-dependent cloud mode factors $\mathrm{MF}_{1,2}, \mathrm{MF}_{3}$, cloud top altitudes $\mathrm{z}_{\mathrm{t}}$, and cloud optical depth altitude profiles $\mathrm{u}(\mathrm{z})$. The same data sets are used in the present study.
Fig. 19 illustrates the 2D fields of zonally and diurnally averaged mean net radiative heating rates in the mesosphere and upper troposphere of Venus when atmospheric temperature profiles according to VIRTIS (display A), VeRa (B), VIRA-2 (C), and VIRA-1 (D) are utilized. Cloud parameters and trace gas abundances are identical in each case. The results for VIRA-1, VIRA-2, and VIRTIS are very similar in correspondence with Figs. 2 and 3. There are two planet-wide net cooling regions located between 72 and $82 \mathrm{~km}$ and between 55 and $62 \mathrm{~km}$, respectively. Both regions show an equator to pole gradient that is especially strong in the upper one. Intermediate layers between 62 and $72 \mathrm{~km}$ are characterized by net heating at low and mid latitudes up to $45^{\circ}$, while net cooling prevails at higher latitudes. Low latitude heating is mainly forced by the presence of the unknown UV absorber. Atmospheric net heating also dominates the low and mid latitudes above $82 \mathrm{~km}$, and net cooling occurs at high latitudes. Below about $55 \mathrm{~km}$, very weak net heating is observed at all latitudes that results from thermal heating of the atmosphere near the cloud base $(48 \mathrm{~km})$. Nearly zero net heating prevails in the deep atmosphere below $44 \mathrm{~km}$ where the troposphere of Venus is almost in radiative equilibrium.

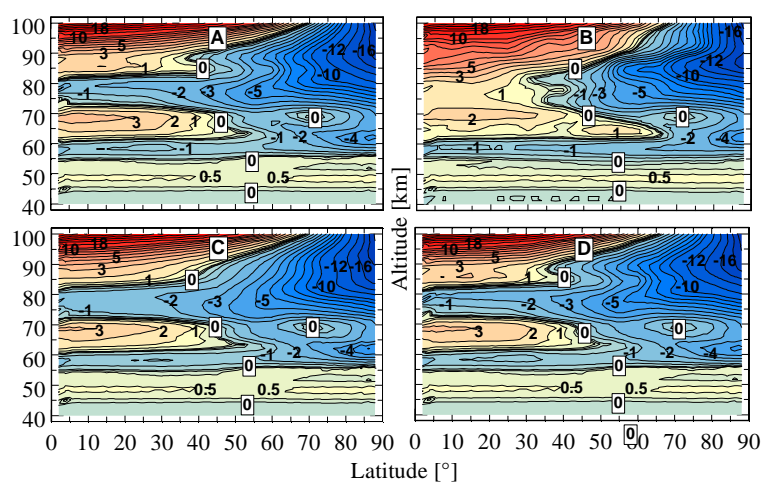

Fig. 19. Zonally and diurnally averaged mean net radiative heating rates $Q^{N}[K /$ day $]$ as functions of latitude and altitude for different temperature data sets. (A) VIRTIS, (B) VeRa, (C) VIRA-2, (D) VIRA1.

The net heating field that is based on VeRa temperatures (Fig. 19B) exhibits some significant differences compared to the other three plots. Since heating rates based on the different temperature models are very similar 
(cf. Figs. 1 and 3), net heating rate differences $\Delta \mathrm{Q}^{\mathrm{N}}$ (VeRa, Other) (not shown here, but see Figure $30 \mathrm{~B}$ in Haus et al. (2016) for $\Delta Q^{N}$ (VeRa, VIRTIS)) are almost exclusively determined by cooling rate differences. Compared with other temperature models, a planet-wide net heating excess is observed in case of $\mathrm{VeRa}$ temperatures at altitudes around $90 \mathrm{~km}$. VeRa net heating is also larger around $80 \mathrm{~km}$ at equatorial and mid latitudes. This causes the loss of the broad, planet-wide net cooling region between 72 and $82 \mathrm{~km}$ obtained for the other temperature fields. Low latitudes at these altitudes are now characterized by a small net heating.

Despite the described net radiative forcing variability for different temperature models and despite the existence of comparatively narrow layers where net radiative cooling occurs at all latitudes, a general conclusion can be drawn. Low latitudes at mesospheric levels are mainly determined by radiative net heating, while dominant net cooling prevails at mid and especially high latitudes. Proceeding in time, this would lead to lower atmospheric temperatures at polar latitudes compared to the tropics. It can be expected therefore that radiative equilibrium temperatures at the poles are significantly lower than observed temperatures. To maintain the observed thermal structure, which is characterized by increasing temperatures with (absolute) latitude and temperature maxima near the poles, nonradiative processes must play an important role in the mesosphere of Venus that cool the low latitude belts and concurrently warm the polar regions.

Thus, it is a very interesting task to determine latitude-dependent radiative equilibrium temperatures $\mathrm{T}^{\mathrm{RE}}(\mathrm{z}, \varphi)$ of the atmosphere. Differences between $\mathrm{T}^{\mathrm{RE}}(\mathrm{z}, \varphi)$ and $\mathrm{T}^{\mathrm{Obs}}(\mathrm{z}, \varphi)$, the observed thermal structure, are very indicative for the role of dynamical processes that act to destroy the thermal structure primarily induced by pure radiation processes.
Radiative equilibrium at each altitude and geographic latitude occurs when the overall net flux divergences approach zero, $\mathrm{dF}^{\mathrm{N}}(\mathrm{z}, \varphi) / \mathrm{dz}=0$, leading to net radiative heating rates $\mathrm{Q}^{\mathrm{NRE}}(\mathrm{z}, \varphi)=0$. The radiative equilibrium temperature profile is determined by repeated modifications of the basis temperature value at each level of the atmosphere by small perturbation steps $( \pm 1$ $\mathrm{K}$ or $\pm 0.1 \mathrm{~K}$ ) until convergence (i.e., $\mathrm{Q}^{\mathrm{NRE}}=0$ ) is achieved at each grid point in the altitude-latitude space.

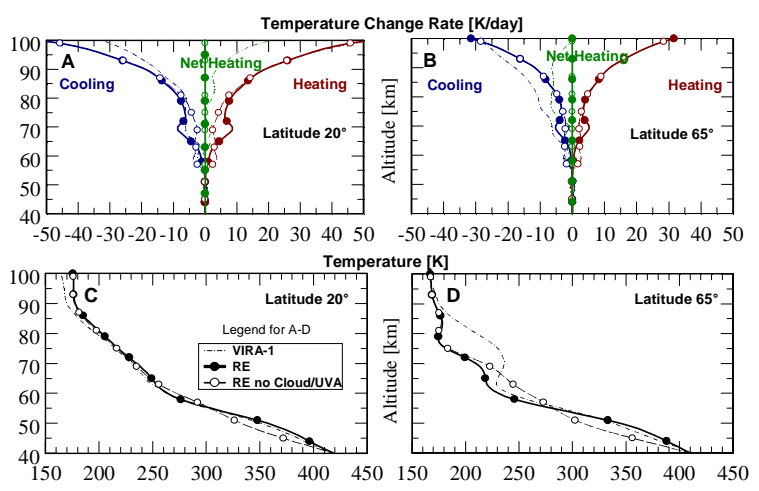

Fig. 20. Comparison of zonally averaged mean temperature change rates and corresponding temperature profiles at $20^{\circ}$ (A and $\mathrm{C}$ ) and $65^{\circ}$ (B and D) for VIRA-1 and radiative equilibrium (RE) conditions.

Fig. 20 compares basis and radiative equilibrium (RE) temperature change rates (cooling, heating, net heating) at 20 and $65^{\circ}$ (displays A and B) and corresponding temperature profiles (displays $\mathrm{C}$ and $\mathrm{D}$ ). Heating rates $Q^{\mathrm{HRE}}$ only marginally change as expected, but cooling rates $\mathrm{Q}^{\mathrm{CRE}}$ heavily deviate from the basis profiles that refer to temperature conditions according to VIRA1. At low latitudes and for nominal cloud and UVA distribution, much stronger thermal cooling occurs in RE at most altitudes (mainly above $80 \mathrm{~km}$ and near 70 $\mathrm{km}$ ), while much weaker cooling prevails at $65^{\circ}$. The corresponding radiative equilibrium temperature $\mathrm{T}^{\mathrm{RE}}$ at $20^{\circ}$ is higher than VIRA1 above about $63 \mathrm{~km}$ but slightly lower at levels between 63 and $55 \mathrm{~km}$. In contrast, a hypothetical cloud and UVA free atmosphere would exhibit higher $\mathrm{T}^{\mathrm{RE}}$ values even below $63 \mathrm{~km}$ but smaller $\mathrm{T}^{\mathrm{RE}}$ values below $55 \mathrm{~km}$. At $65^{\circ}$ latitude and for nominal cloud and UVA distribution, $\mathrm{T}^{\mathrm{RE}}$ is significantly lower than VIRA-1 at all 
altitudes above $55 \mathrm{~km}$. Maximum deviations reach $-55 \mathrm{~K}$ near $75 \mathrm{~km}$. Neglect of cloud and UVA influences would produce higher $\mathrm{T}^{\mathrm{RE}}$ values between 55 and $67 \mathrm{~km}$ and smaller ones below $55 \mathrm{~km}$. The partly large differences between the 'RE' and 'RE no cloud/UVA' curves in all four displays accentuates the large influence of clouds and the UV absorber on the radiative energy budget of Venus' atmosphere.

Fig. 21 provides the complete $2 \mathrm{D}$ picture of zonally averaged mean cooling rates $Q^{C}$ for VIRA-1 (display A) and resulting changes $\Delta \mathrm{Q}^{\mathrm{C}}(\mathrm{RE}, \mathrm{VIRA}-1)=\mathrm{Q}^{\mathrm{C}}(\mathrm{RE})-\mathrm{Q}^{\mathrm{C}}(\mathrm{VIRA}-1)$ (display $\mathrm{B}$ ) when radiative equilibrium conditions are attained. Positive values characterize weaker RE cooling. Fig. 22 shows the corresponding 2D temperature field (display $\mathrm{A}$ ) and differences $\Delta \mathrm{T}(\mathrm{RE}$, VIRA-1) $=\mathrm{T}(\mathrm{RE})-\mathrm{T}($ VIRA-1) $($ display B $)$. Positive values indicate higher temperatures for the equilibrium case. As already pointed out above, radiative equilibrium conditions are almost exclusively determined by changes of thermal cooling rates. The zero isoline for both $\Delta Q^{C}$ and $\Delta T$ at altitudes between 65 and $95 \mathrm{~km}$ is located between 25 and $60^{\circ}$. Stronger RE cooling and higher RE temperatures compared with observational data are found equatorward of the zero isolines, while less cooling and much lower RE temperatures determine the poleward directed branch. There is an exception near $60 \mathrm{~km}$ where a narrow range of colder air extends equatorward to $25^{\circ}$. Polar RE temperatures above the cloud top (60-70 km) are up to $70 \mathrm{~K}$ lower and equatorial temperatures near the mesopause up to $10 \mathrm{~K}$ higher than observed values. Averaging RE temperatures at the equator and at the pole at altitudes between 65 and $100 \mathrm{~km}$, polar temperatures would be about $35 \mathrm{~K}$ lower than in the tropics. The values of $70 \mathrm{~K}$ and $35 \mathrm{~K}$ are similar to the results reported by Crisp (1989) who found 60 and $40 \mathrm{~K}$, respectively.

Since the observed atmospheric thermal structure in the upper mesosphere is characterized by increasing temperatures with latitude with maxima near the pole,

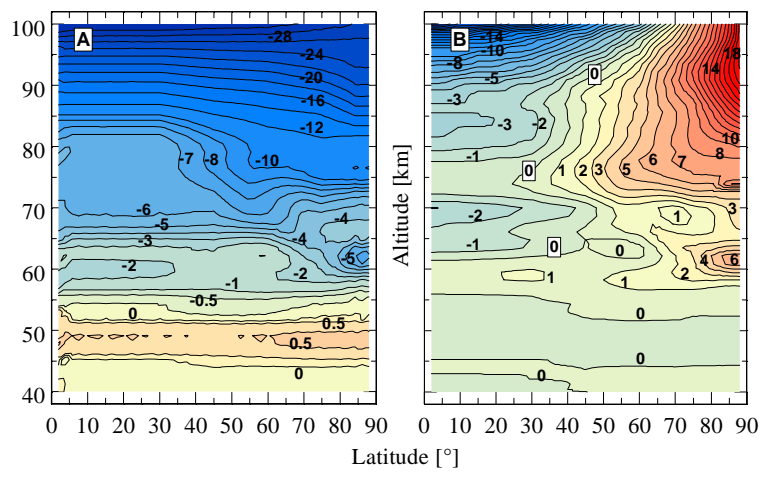

Fig. 21. Zonally averaged mean cooling rates $Q^{C}$ for VIRA-1 temperature structure (A) and cooling rate changes $\Delta Q^{C}$ for radiative equilibrium conditions vs. VIRA-1 (B) as functions of latitude and altitude. $\mathrm{Q}^{\mathrm{C}}$ and $\Delta \mathrm{Q}^{\mathrm{C}}$ are given in [K/day].

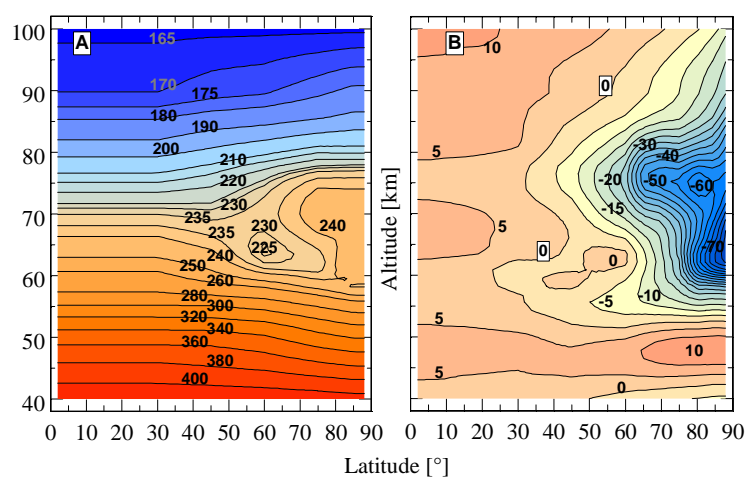

Fig. 22. Zonally averaged mean atmospheric temperatures (VIRA-1) (A) and temperature changes $\Delta \mathrm{T}$ for radiative equilibrium conditions vs. VIRA-1 (B) as functions of latitude and altitude. $\mathrm{T}$ and $\Delta \mathrm{T}$ are given in $[\mathrm{K}]$.

Crisp (1989) already concluded that this structure can only be maintained by dynamical processes. A possible mechanism would involve a meridional circulation characterized by rising motion at low latitudes, poleward heat flow, and subsidence at high latitudes. According to Fig. 22B, the poleward flow would be especially strong near $75 \mathrm{~km}$.

\section{Summary and conclusions}

Thermal cooling rates $\mathrm{Q}^{\mathrm{C}}$ and solar heating rates $\mathrm{Q}^{\mathrm{H}}$ in the atmosphere of Venus at altitudes between 0 and $100 \mathrm{~km}$ are investigated using the radiative transfer and radiative balance simulation techniques described by Haus et al. (2015b, 2016). The calculations are separately performed for 
thermal (1.67-1000 $\mu \mathrm{m})$ and solar (0.125$1000 \mu \mathrm{m})$ flux components.

Pure temperature effects on zonally averaged thermal cooling rates $\mathrm{Q}^{\mathrm{C}}$ are strongest pronounced at altitudes above $60 \mathrm{~km}$ where $\mathrm{Q}^{\mathrm{C}}$ usually increases with increasing temperature (Figs. 1 and 2). Cloud influences may additionally alter these results between 55 and $85 \mathrm{~km}$ (Figs. 4A and 15) where $\mathrm{Q}^{\mathrm{C}}$ usually increases with increasing cloud mode 2 abundance at altitudes above $65 \mathrm{~km}$. Solar heating rates $\mathrm{Q}^{\mathrm{H}}$ also strongly depend on latitude, but mainly due to decreasing insolation with increasing distance from equator resulting in much smaller heating rates at high latitudes. Heating rates generally respond much weaker to temperature and cloud parameter changes than cooling rates do (Figs. 1 and 3). They are almost insensitive to small temperature changes below $70 \mathrm{~km}$. As in case of cooling, cloud influences occur at altitudes between 55 and $85 \mathrm{~km}$ (Figs. 4B and 17) where increasing cloud mode 2 abundance slightly intensifies $Q^{\mathrm{H}}$ at altitudes above $70 \mathrm{~km}$. Variations of the unknown UV absorber abundance may additionally alter $\mathrm{Q}^{\mathrm{H}}$ profiles (Fig. 5). The nominal model doubles heating at $70 \mathrm{~km}$ and low latitudes compared with a neglect of this opacity source.

Accurate radiative cooling and heating calculations require huge amounts of processing time in the order of hours (especially in case of solar heating). It is impossible to incorporate them into General Circulation Models (GCMs) that are applied to study atmospheric circulation processes. A parameterization approach is developed that permits a fast calculation of $\mathrm{Q}^{\mathrm{C}}$ and $\mathrm{Q}^{\mathrm{H}}$ at altitudes between 0 and $100 \mathrm{~km}$ separating temperature, cloud parameter, and unknown UV absorber influences.

The temperature response parameterization relies on a pre-described altitude and latitude- dependent cloud model. It is based on an algorithm that characterizes Q responses to a broad range of temperature perturbations at each level of the atmosphere using VIRA-1 as basis temperature model
(Fig. 8). Actual latitude and altitudedependent Q values are calculated considering the differences between actual and basis temperature fields and summing up the temperature perturbation matrices. Cooling rate errors of the procedure do not exceed $\pm 0.1 \mathrm{~K} /$ day at altitudes below $70 \mathrm{~km}$ for the investigated cases where VIRA-1 temperature profiles are substituted by VIRA-2 profiles or by retrieved profiles obtained from VIRTIS and VeRa data analyses (Figs. 9, 10, and 12). They sometimes reach $\pm(0.2-0.3) \mathrm{K} /$ day between 70 and $90 \mathrm{~km}$. Synthetic temperature profiles (e.g. VIRA-1 $+10 \mathrm{~K}$ ) produce slightly larger parameterization errors above $70 \mathrm{~km}$. This may indicate that the parameterization approach works best in cases where the target temperature profiles multiply intersect the basis profile. Solar heating rate errors are less than $\pm 0.01 \mathrm{~K} /$ day below $70 \mathrm{~km}$ and do not exceed $\pm 0.1 \mathrm{~K} /$ day up to $90 \mathrm{~km}$. Larger deviations up to $\pm 1 \mathrm{~K} /$ day may occur near $100 \mathrm{~km}$.

The cloud response parameterization is based on accurate calculations for a range of cloud mode factors $\left(\mathrm{MF}_{1,2}{ }^{*}\right.$ for modes 1 and 2, $\mathrm{MF}_{3}{ }^{*}$ for mode 3) that additionally change cloud optical depths as determined by the initial latitude-dependent model. In case of thermal cooling, calculations are performed for different temperature models (Fig. 14). Average response matrices (Fig. 15) are eventually used. They produce maximum cooling rate errors of $\pm 0.3 \mathrm{~K} /$ day near $75 \mathrm{~km}$ in case of $\mathrm{MF}_{1,2}{ }^{*}=1.5$ (Fig. 16) and \pm 0.04 $\mathrm{K} /$ day near $55 \mathrm{~km}$ in case of $\mathrm{MF}_{3}{ }^{*}=1.5$. Such errors can be well tolerated considering the achieved saving of required computer resources compared with accurate calculations. Moreover, these errors depend approximately linearly on the mode factor change and become much smaller for mode factor variations in the order of $10-20 \%$. Since solar heating rates generally respond much weaker to temperature and cloud parameter changes than cooling rates do, the cloud parameter response parameterization of $\mathrm{Q}^{\mathrm{H}}$ only considers the VIRA-1 temperature model (Fig. 17). Maximum errors due to other temperature models are in 
Haus, R., et al., ICARUS 284, 216-232 (2017)

the order of $\pm 0.02 \mathrm{~K} /$ day near $75 \mathrm{~km}$. The $\mathrm{Q}^{\mathrm{H}}$ response parameterization for abundance changes of the unknown UV absorber is performed in a similar way. Maximum errors due to the use of other temperature models or other cloud parameters do not exceed \pm 0.05 $\mathrm{K} /$ day near $70 \mathrm{~km}$.

The proposed approach to parameterize thermal cooling and solar heating rates in the atmosphere of Venus considerably differs from that used by Mendonca et al. (2015). These authors have developed a fast singlecolumn radiative transfer model that is very suitable for GCM applications with temperature change rate $(\mathrm{Q})$ computational times much shorter than $1 \mathrm{~s}$ for one atmospheric column in both the solar and thermal ranges. The method is based on a number of quite rough radiative transfer approximations that nevertheless achieve accuracies of computed Q's in the order of 10-20\%. Present calculations require a huge (but onetime) amount of computational effort to determine sets of $\mathrm{Q}$ perturbation matrices that are based on accurate and spectrally highly resolved radiative transfer flux calculations. The subsequently developed parameterization technique, however, produces $\mathrm{Q}$ tables where the deviations between accurate calculation and parameterization results are in the order of a few tenths of K/day at altitudes below $90 \mathrm{~km}$ at typical processing times of $3 \mathrm{~s}$ for the complete latitude-altitude 2D field.

The parameterization algorithm is used to calculate radiative equilibrium (RE) temperatures in the atmosphere of Venus
Doi: 10.1016/j.icarus.2016.11.025 Preprint

(Figs. 20-22). Mesospheric RE temperatures above the cloud top at the poles are up to 70 $\mathrm{K}$ lower and equatorial temperatures up to 10 $\mathrm{K}$ higher than observed values (e.g. VIRA-1) resulting in an average equator to pole gradient of about $35 \mathrm{~K}$. The observed thermal structure can only be maintained by dynamical processes.

\section{Appendix}

Table A1 displays the initial or basis temperature model (VIRA-1) at altitudes between 100 and $40 \mathrm{~km}$ at four selected latitudes and resulting initial cooling rates $\mathrm{Q}^{\mathrm{C}}$ and heating rates $\mathrm{Q}^{\mathrm{H}}$. Note that $\mathrm{Q}^{\mathrm{C}}$ and $\mathrm{Q}^{\mathrm{H}}$ in the table reflect values obtained from accurate calculations. They correspond to the corrected values $\alpha^{\mathrm{C}} \mathrm{Q}_{0}{ }^{\text {CMatrix }}$ and $\alpha^{\mathrm{H}} \mathrm{Q}_{0}{ }^{\text {HMatrix }}$ according to Eq. (6). The data required to apply the parameterization method are available from the authors upon request.

\section{Acknowledgments}

R.H. is funded by the German Research Foundation under grant number HA 2887/22. We acknowledge the work of the VIRTIS/VEX and VeRa/VEX teams and also the entire Venus Express team of ESA and Astrium, who made the measurement data available that were used in this study. 
Haus, R., et al., ICARUS 284, 216-232 (2017) Doi: 10.1016/j.icarus.2016.11.025 Preprint

Table A1. Temperature model (T $[\mathrm{K}]$ ) according to VIRA-1 and accurate calculation results for thermal cooling rates $\left(Q^{\mathrm{C}}[\mathrm{K} /\right.$ day $\left.]\right)$ and solar heating rates $\left(\mathrm{Q}^{\mathrm{H}}[\mathrm{K} /\right.$ day $\left.]\right)$. Temperature profiles above $90 \mathrm{~km}$ result from linear interpolations between VIRA-1 at $90 \mathrm{~km}$ and a fixed value of 165 $\mathrm{K}$ at $100 \mathrm{~km} . \mathrm{z}$ : altitude $[\mathrm{km}], \varphi$ : latitude $\left[^{\circ}\right]$.

\begin{tabular}{|c|c|c|c|c|c|c|c|c|c|c|c|c|}
\hline $\mathrm{z} / \varphi$ & \multicolumn{3}{|c|}{20} & \multicolumn{3}{|c|}{45} & \multicolumn{3}{|c|}{65} & \multicolumn{3}{|c|}{80} \\
\hline & $\mathrm{T}$ & $Q^{C}$ & $\mathrm{Q}^{\mathrm{H}}$ & $\mathrm{T}$ & $Q^{C}$ & $\mathrm{Q}^{\mathrm{H}}$ & $\mathrm{T}$ & $Q^{C}$ & $\mathrm{Q}^{\mathrm{H}}$ & $\mathrm{T}$ & $\mathrm{Q}^{\mathrm{C}}$ & $\mathrm{Q}^{\mathrm{H}}$ \\
\hline 100 & 165.0 & -32.4 & 53.0 & 165.0 & $\begin{array}{l}-31.3 \\
\end{array}$ & 44.0 & 165.0 & -30.2 & 31.8 & 165.0 & -28.3 & 18.1 \\
\hline 98 & 165.9 & -27.8 & 42.3 & 166.5 & -27.4 & 35.4 & 167.1 & -27.1 & 25.9 & 168.0 & -26.3 & 15.1 \\
\hline 96 & 166.8 & -23.9 & 34.6 & 167.9 & -24.3 & 29.2 & 169.1 & -24.6 & 21.5 & 170.8 & -25.0 & 12.5 \\
\hline 94 & 167.6 & -20.8 & 28.8 & 169.4 & -21.6 & 24.3 & 171.2 & -22.6 & 17.8 & 173.8 & -23.9 & 10.1 \\
\hline 92 & 168.5 & -17.8 & 23.7 & 170.8 & -18.9 & 19.9 & 173.2 & -20.3 & 14.4 & 176.8 & -22.5 & 8.05 \\
\hline 90 & 169.4 & -15.3 & 19.1 & 172.3 & -16.5 & 16.0 & 175.3 & -17.8 & 11.5 & 179.7 & -20.5 & 6.60 \\
\hline 88 & 173.6 & -13.3 & 15.9 & 176.6 & -14.5 & 13.4 & 179.7 & -15.7 & 9.67 & 184.4 & -18.1 & 5.54 \\
\hline 86 & 178.2 & -11.0 & 13.6 & 181.8 & -12.7 & 11.5 & 185.1 & -14.1 & 8.18 & 189.6 & -15.8 & 4.51 \\
\hline 84 & 183.8 & -8.66 & 11.6 & 188.6 & -10.9 & 9.79 & 193.2 & -12.7 & 6.70 & 197.4 & -13.9 & 3.58 \\
\hline 82 & 189.9 & -6.90 & 9.68 & 195.5 & -9.38 & 8.18 & 201.6 & -11.6 & 5.33 & 205.8 & -12.3 & 2.89 \\
\hline 80 & 197.1 & -5.98 & 8.21 & 202.5 & -8.33 & 7.00 & 210.4 & -10.7 & 4.32 & 214.3 & -10.9 & 2.41 \\
\hline 78 & 205.3 & -6.18 & 7.19 & 210.4 & -8.49 & 6.17 & 219.5 & -10.3 & 3.68 & 224.5 & -11.0 & 2.05 \\
\hline 76 & 212.1 & -6.27 & 6.54 & 216.2 & -8.20 & 5.58 & 227.6 & -9.77 & 3.25 & 235.0 & -11.4 & 1.75 \\
\hline 74 & 218.6 & -6.20 & 6.21 & 221.0 & -7.44 & 5.22 & 232.4 & -8.14 & 3.06 & 240.4 & -9.26 & 1.59 \\
\hline 72 & 224.1 & -6.10 & 6.86 & 224.6 & -6.71 & 5.66 & 235.1 & -6.75 & 3.77 & 242.6 & -6.51 & 2.04 \\
\hline 70 & 229.8 & -6.14 & 8.57 & 228.2 & -6.19 & 6.87 & 236.0 & -6.28 & 5.27 & 243.8 & -5.01 & 2.93 \\
\hline 68 & 235.4 & -5.90 & 7.72 & 231.9 & -5.53 & 5.83 & 234.7 & -6.15 & 4.55 & 243.1 & -4.02 & 2.30 \\
\hline 66 & 241.0 & -4.30 & 5.55 & 235.8 & -4.06 & 3.93 & 231.4 & -5.38 & 2.99 & 240.2 & -3.27 & 1.36 \\
\hline 64 & 245.4 & -1.87 & 3.38 & 240.7 & -2.27 & 2.33 & 228.4 & -3.04 & 1.66 & 239.6 & -4.12 & 0.84 \\
\hline 62 & 254.5 & -1.87 & 2.04 & 246.2 & -1.74 & 1.40 & 230.4 & -1.52 & 0.87 & 240.1 & -5.57 & 0.47 \\
\hline 60 & 262.8 & -2.33 & 1.42 & 253.3 & -1.60 & 0.97 & 241.2 & -2.05 & 0.58 & 240.0 & -4.28 & 0.23 \\
\hline 58 & 275.2 & -1.90 & 0.97 & 267.4 & -1.40 & 0.65 & 256.8 & -2.08 & 0.39 & 244.1 & -2.01 & 0.15 \\
\hline 56 & 291.8 & -0.50 & 0.48 & 290.2 & -0.75 & 0.33 & 278.5 & -0.74 & 0.20 & 263.8 & -0.45 & 0.07 \\
\hline 54 & 312.8 & -0.04 & 0.21 & 312.3 & -0.19 & 0.15 & 300.0 & -0.08 & 0.08 & 285.2 & -0.02 & 0.03 \\
\hline 52 & 322.2 & -0.08 & 0.11 & 332.5 & -0.01 & 0.08 & 320.8 & -0.09 & 0.04 & 305.6 & -0.03 & 0.01 \\
\hline 50 & 350.5 & +0.46 & 0.05 & 349.7 & +0.41 & 0.04 & 337.7 & +0.48 & 0.02 & 323.2 & +0.52 & 0.01 \\
\hline 48 & 366.4 & +0.60 & 0.02 & 364.6 & +0.52 & 0.02 & 352.5 & +0.76 & 0.01 & 340.3 & +0.86 & 0.00 \\
\hline 46 & 379.7 & +0.03 & 0.01 & 376.1 & +0.07 & 0.01 & 367.1 & +0.12 & 0.00 & 357.0 & +0.17 & 0.00 \\
\hline 44 & 391.2 & -0.02 & 0.01 & 388.3 & +0.00 & 0.01 & 382.1 & -0.00 & 0.00 & 375.0 & -0.02 & 0.00 \\
\hline 42 & 403.5 & +0.01 & 0.01 & 401.6 & -0.01 & 0.01 & 397.8 & -0.03 & 0.00 & 292.4 & -0.04 & 0.00 \\
\hline 40 & 4 & +0.00 & 0.01 & 415.5 & +0.00 & 1 & 41 & -0.02 & 0.00 & 409.9 & -0.04 & 0.00 \\
\hline
\end{tabular}

\section{References}

Arnold, G., Haus, R., Kappel, D., Piccioni, G., Drossart, P., 2012. VIRTIS/VEX observations of Venus: Overview of selected scientific results. J. Appl. Remote Sensing 6, 20 pp.,

http://dx.doi.org/10.1117/1.JRS.6.063580.

Crisp, D., 1986. Radiative forcing of the Venus mesosphere: I. Solar fluxes and heating rates. Icarus 67(3), 484-514, $\quad$ http://dx.doi.org/10.1016/0019$\underline{1035(86) 90126-0 .}$.

Crisp, D., 1989. Radiative forcing of the Venus mesosphere: II. Thermal fluxes, cooling rates, and radiative equilibrium temperatures. Icarus $77(2), 391-$ 413,http://dx.doi.org/10.1016/0019-1035(89)90096-1.
Drossart, P., Piccioni, G., Adriani, A., Angrilli, F., Arnold, G. et al., 2007. Scientific goals for the observation of Venus by VIRTIS on ESA/Venus express mission. Planet. Space Sci. 55(12), 16531672, http://dx.doi.org/10.1016/j.pss.2007.01.003.

Eymet, V., Fournier, R., Dufresne, J.L., Lebonnois, S., Hourdin, F., Bullock, M.A., 2009. Net exchange parameterization of thermal infrared radiative transfer in Venus' atmosphere. J. Geophys. Res. 114(E11008), http://dx.doi.org/10.1029/2008JE003276.

Haus, R., Kappel, D., Arnold, G., 2013. Selfconsistent retrieval of temperature profiles and cloud structure in the northern hemisphere of Venus using VIRTIS/VEX and PMV/VENERA-15 radiation measurements. Planet. Space Sci. 89, 77-101, http://dx.doi.org/10.1016/j.pss.2013.09.020. 
Haus, R., et al., ICARUS 284, 216-232 (2017)

Haus, R., Kappel, D., Arnold, G., 2014. Atmospheric thermal structure and cloud features in the southern hemisphere of Venus as retrieved from VIRTIS/VEX radiation measurements. Icarus 232C, 232-248, http://dx.doi.org/10.1016/j.icarus.2014.01.020.

Haus, R., Kappel, D., Arnold, G., 2015a. Lower atmosphere minor gas abundances as retrieved from Venus Express VIRTIS-M-IR data at $2.3 \mu \mathrm{m}$. Planet. Space Sci. 105, 159-174,

http://dx.doi.org/10.1016/j.pss.2014.11.020.

Haus, R., Kappel, D., Arnold, G., 2015b. Radiative heating and cooling in the middle and lower atmosphere of Venus and responses to atmospheric and spectroscopic parameter variations. Planet. Space Sci. 117, 262-294, http://dx.doi.org/10.1016/j.pss.2015.06.024.

Haus, R., Kappel, D., Tellmann, S., Arnold, G., Piccioni. G., Drossart, P., Häusler, B., 2016. Radiative energy balance of Venus based on improved models of the middle and lower atmosphere. Icarus 272, 178205, http://dx.doi.org/10.1016/j.icarus.2016.02.048.

Häusler, B., Pätzold, M., Tyler, G.L., Simpson, R.A., Bird, M.K. et al., 2006. Radio science investigations by VeRa anboard the Venus Express spacecraft. Planet. Space Sci. 54(13-14), 1315-1335, http://dx.doi.org/10.1016/j.pss.2006.04.032.

Keating, G.M., Bertaux, J.L., Bougher, S.W., Cravens, T.E., Dickinson, R.E. et al., 1985. Models of Venus neutral upper atmosphere: Structure and composition. In: The Venus International Reference Atmosphere, Kliore, A. J., Moroz, V.I., Keating, G.M. (Eds.), Adv. Space Res. 5(11), 117-171 (1985), http://dx.doi.org/10.1016/0273-1177(85)90200-5.

Lebonnois, S., Hourdin, F., Eymet, V., Crespin, A., Fournier, R., Forget, F., 2010. Superrotation of Venus' atmosphere analysed with a full general circulation model. J. Geophys. Res. 115(E06006), http://dx.doi.org/10.1029/2009JE003458.

Lebonnois, S., Eymet, V., Lee, C., d'Ollone, J.V., 2015. Analysis of the radiative budget of the Venusian atmosphere based on infrared Net Exchange Rate formalism. J. Geophys. Res. (Planets) 120, 1186-1200, http://dx.doi.org/10.1002/2015JE004794.

Lee, C. and Richardson, M.I., 2010. A general circulation model ensemble study of the atmospheric circulation of Venus. J. Geophys. Res. 115(E04002), http://dx.doi.org/10.1029/2009JE003490.

Mendonca, J.M., Read, P.L., Wilson, C.F., Lee, C., 2015. A new, fast and flexible radiative transfer method for Venus general circulation models. Planet. Space Sci. 105, 80-93, http://dx.doi.org/10.1016/j.pss.2014.11.008.
Doi: 10.1016/j.icarus.2016.11.025 Preprint

Moroz, V.I., 1981. The albedo of Venus in the range 0.2-4.0 microns (in Russian). Kosm. Issled. 19(4), 591-598.

Moroz, V.I., Zasova, L., 1997. VIRA-2: A review of inputs for updating the Venus International Reference Atmosphere. Adv. Space Res. 19(8), 1191-1201, http://dx.doi.org/10.1016/S0273-1177(97)00270-6.

Piccioni, G., Drossart, P., Suetta, E., Cosi, M., Ammannito, E. et al., 2007. VIRTIS: The Visible and Infrared Thermal Imaging Spectrometer. ESA Spec. Publ. SP-1295, pp. 1-27, European Space Agency, Paris.

Pollack, J.B., Toon, O.B., Whitten, R.C., Boese, R., Ragent, B. et al., 1980. Distribution and source of the UV absorption in Venus' atmosphere. J. Geophys. Res. 85(A13), 8141-8150,

http://dx.doi.org/10.1029/JA085iA13p08141.

Rodin, A.V., Mingalev, I.V., Orlov, K.G., 2013. Transition between zonal superrotation and subsolarantisolar circulation of the Venus atmosphere: results of the non-hydrostatic general circulation model. EPSC Abstracts Vol. 8, EPSC2013-924.

Schubert, G., Bougher, S.W., Covey, C.C., Del Genio, A.D., Grossmann, A.S. et al., 2007. Venus atmosphere dynamics: A continuing enigma. In Exploring Venus as a Terrestrial Planet, Esposito, L.W., Stofan, E.R., and Cravens, T.E. (Eds.), AGU Geophysical Monograph Series 176, 101-120, ISBN: 978-0-87590-441-2,http://dx.doi.org/10.1029/GM176.

Seiff, A., Schofield, J.T., Kliore, A.J., Taylor, F.W., Limaye, S.S. et al., 1985. Models of the structure of the middle atmosphere of Venus from the surface to 100 kilometers altitude. In: The Venus International Reference Atmosphere, Kliore, A. J., Moroz, V.I., Keating, G.M. (Eds.), Adv. Space Res. 5(11), 3-58 (1985),

http://dx.doi.org/10.1016/0273-1177(85)90197-8.

Tellmann, S., Pätzold, M., Häusler, B., Bird, M.K., Tyler, G.L., 2009. Structure of the Venus neutral atmosphere as observed by the Radio Science experiment VeRa on Venus Express. J. Geophys. Res. 114(E00B36), 354-372,

http://dx.doi.org/10.1029/2008JE003204.

Tellmann, S., Häusler, B., Hinson, D.P., Tyler, G.L., Andert, T.P. et al., 2012. Small-scale temperature fluctuations seen by the VeRa Radio Science Experiment on Venus Express. Icarus 221(2), 471480, http://dx.doi.org/10.1016/j.icarus.2012.08.023.

Zasova, L.V., Moroz, V.I., Linkin, V.M., Khatuntsev, I.V., Maiorov, B.S., 2006. Structure of the Venusian atmosphere from surface up to $100 \mathrm{~km}$. Cosmic Res. 44(4), 364-383,

http://dx.doi.org/10.1134/S0010952506040095. 